\title{
Identificação de áreas para o florestamento no espaço total do Brasil
}

\author{
AZIZ AB 'SÁBER, JOSÉ GOLDEMBERG, LEOPOLDO \\ RODÉS E WERNER ZULAUF
}

\section{Antecedentes - Efeito estufa}

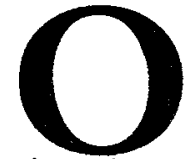

$s$ efeitos de poluição oriunda de diversas fontes vêm sendo estudados intensamente nas últimas décadas.

A poluição das águas já chegou a ser reduzida virtualmente em inúmeros casos, no que concerne a sólidos suspensos, demanda bioquímica de oxigênio, $\mathrm{pH}$ e um grande rol de substâncias químicas, promovendo um incipiente retorno de determinadas espécies de peixes aos rios, lagos, estuários e mares antes comprometidos. Em relação às áreas excessivamente urbanizadas e industrializadas ainda estamos muito longe de soluçóes completas: constatação válida do Primeiro ao Terceiro Mundo.

A poluição do ar também tem sido controlada em muitas chaminés e canos de escape, graças a filtros de manga e eletrostáticos para conter poeiras em suspensão, e lavagens químicas e catalisadores para remoção de gases poluentes. Visa-se especialmente reduzir emissóes de óxidos de enxofre, óxidos de nitrogênio, hidrocarbonetos, monóxido de carbono, cloro, flúor, amônia, metais pesados e organoclorados, para citar apenas alguns dos parâmetros mais comuns. Entrementes, tem sido muito difícil obter melhorias expressivas na qualidade do ar em detérminados bolsóes climáticos sujeitos a calmarias persistentes.

As açóes de controle da poluiçăo investem agora contra os depósitos de lixo, e os rejeitos industriais e de mineraçáo, que, ao contrário das emissōes líquidas e gasosas, não se diluem no meio ambiente, mas se acumulam perigosamente em terrenos que vão sendo ocupados pela urbanização da periferia das cidades, locais onde tem havido sérios problemas de contaminação. As despesas para remoçáo e limpeza dessas áreas têm sido enormes, tanto por parte das indústrias como por parte dos governos. 
Recentemente, novas formas de poluição passaram a desafiar. autoridades, técnicos e cientistas, na medida em que substâncias aparentemente inócuas $\mathrm{e}$ inertes como o gás carbônico e os clorofluorcarbonetos passaram a se revelar como causadores de efeitos globais, não mais localizados ou regionais, mas ameaçando a biosfera como um todo, particularmente por perturbaçóes na sua parte mais frágil, a atmosfera.

A magnitude dos problemas está a exigir soluçóes na mesma dimensão. O controle das consequiências da reduçăo da camada de ozônio da estratosfera, provocada pelos gases CFC, (clorofluorcarbonos), induziu a abertura de novos caminhos para entendimentos de caráter global e assim foi firmado um grande compromisso internacional - Convenção de Viẹna (1985) e Protocolo de Montreal (1987) - com vigência desde o início de 1989. Tais documentos estabelecem metas físicas para a redução gradativa da produçáo dos $\mathrm{CFC}$, estimada em mais de um milhão de toneladas anuais, até o final do século.

Apesar da magnitude dos objetivos e das metas físicas estabelecidas, esse problema será resolvido por modificações ou substituiçóes de processos em fábricas dispersas por todo o mundo, mas pertencentes a umas poucas dezenas de empresas, todas empenhadas em encontrar as alternativas brandas - em termos de potencial de reduçăo de ozônio estratosférico - para os produtos que hoje utilizam CFC.

No caso do "efeito estufa", o problema é muito mais complexo na medida em que é maior o número de causas do fenômeno, $\mathrm{e}$ principalmente por causa da extensa dispersão das origens pontuais de emissão de $\mathrm{CO}_{2}$ constituindo miríades de pequenas, médias e grandes fontes.

Uma parte significativa do "efeito estufa" será controlada simultaneamente com a substituição dos CFC, já que esses gases são responsáveis por $17 \%$ do fenômeno, desde que as alternativas em desenvolvimento sejam menos retentoras de calor do que os CFC.

Outra fraçáo importante na equaçáo responsável pelo "efeito estufa" é a do metano ( $\left.\mathrm{CH}_{4}\right)$, que contribui com $19 \%$ para o incremento do fenômeno. Como as principais fontes emissoras antropogênicas são agriculturas irrigadas (arroz, por exemplo), torna-se difícil agir no sentido de controlar o problema por esse lado. Outras fontes importantes de $\mathrm{CH}_{4}$ sáo os manguezais e os banhados, sendo o Pantanal do Mato Grosso uma expressiva área emissora natural. 
A maior causa do efeito estufa, entretanto, situa-se nas emissóes de $\mathrm{CO}_{2}$ que representam $\mathbf{5 0 \%}$ do fenômeno. Entre as formas emissoras antropogênicas destacam-se as queimas de combustíveis fósseis (petróleo, carvão e gás natural) em indústrias, nas termoelétricas, nos automóveis e nas habitaçóes (calefação, no inverno). Têm ịmportância expressiva, também, as queimadas periódicas de fitomassa para preparação do solo para o plantio e as grandes queimadas de florestas nativas.

\section{Carbono na biosfera}

O destino final do excedente de carbono lançado na atmosfera, desde o início da revoluçáo industrial em 1850, é o fundo dos oceanos, onde, sob a forma de carbonatos e bicarbonatos, estão depositados $41.000 \mathrm{Gt}(41 \times 1012 \mathrm{t})$ de $\mathrm{C}(97 \%$ do total), enquanto a atmosfera retém $700 \mathrm{Gt}(1,6 \%)$ e toda a biomassa terrestre, apenas $600 \mathrm{Gt}$ $(1,4 \%)$ (vide Anexo A).

A nuptura do equilibrio climático poderá ser desencadeada

por diversos

mecanismos. $O$ mais estudado é o efeito da

" realimentação positiva" do aquecimento da terra sobre si mesmo.
A transferência do $\mathrm{CO}_{2}$ excedente da atmosfera para os oceanos náo se dá na mesma velocidade que as emissóes das fontes antropogênicas para a atmosfera. Esse descompasso provocou, desde 1850 até hoje, um incremento de concentração de 290 para $345 \mathrm{ppm}$, o que significa $115 \mathrm{Gt}$ ( 115 bilhōes de toneladas) de carbono excedente no ar. Nesse ritmo, já podem ser previstas, com um nível de confiabilidade razoável, algumas perturbaçóes climáticas, e uma elevação significativa do nível dos oceanos em decorrência do efeito estufa (vide Anexo B).

A reversão desse processo impóe-se com urgência para que não ocorram efeitos sinergéticos capazes de romper a elasticidade dos fenômenos meteorológicos, quebrando bruscamente o equilíbrio climático, com o que seriam provocadas catástrofes em dimensóes imprevisíveis.

A ruptura do equilíbrio climático poderá ser desencadeada por diversos mecanismos. O mais estudado é o efeito da "realimentaçáo positiva" do aquecimento da terra sobre si mesma. Sabe-se que a fotossíntese pouco se altera com o aquecimento; sua maior sensibilidade está afeta à luz, à água e aos nutrientes. A respiraçáo, entretanto, e principalmente a decomposiçáo, aumentam sensivelmente com o aquecimento, mormente nas regiōes temperadas e frias, no inverno. Esse fenômeno tem conseqüiências desastrosas nas latitudes médias e altas do hemisfério norte, onde está a maior massa continental (75\%) do planeta e as vastas extensóes de florestas caducifólias, de coníferas, de planícies boreais e de tundra. 
O desequilíbrio fotossíntese - respiração e o aquecimento progressivo que dele resulta são fenômenos localizados nas regiōes temperadas $e$ frias do hemisfério norte, para as quais a elevação da temperatura prevista é o dobro da média global.

Outro efeito sinergético preocupante é a ampliaçáo da evaporação provocada pelo aumento da temperatura. Como o vapor d'água também produz o "efeito estufa"; a maior concentraçăo de umidade no ar tende a aumentar ainda mais a retençáo de calor,"o que provocará mais evaporação. Neste fenômeno, estuda-se o efeito de "freio" do processo, que pode representar a maior quantidade de nuvens formadas com o aumento da umidade. Resta verificar se as nuvens adicionais irão refletir calor em quantidade equivalente ao que é retido pela umidade adicional, deduzindo-se daí se haverá ou náo efeito de causação circular acumulativa de calor.

A ordem de grandëza do tempo disponível para reversão dos níveis de $\mathrm{CO}_{2}$ na atmosfera é de 20 a 30 anos, tempo extremamente escasso para a implantação das transformaçóes energéticas necessárias, diante do vulto, dos custos e demais impactos que tais transformaçōes representam.

Essa premência de tempo torna necessárias, pelo menos, duas açóes simultâneas e complementares: por um lado, a fixaçăo de carbono atmosférico na fitomassa através de um megaprograma florestal, assim alongando o tempo disponível para, por outro lado, implantar tecnologias energéticas (como a de hidrogênio, entre outras) visando uma drástica redução das emissóes de $\mathrm{CO} 2$.

O reflorestamento dá uma resposta rápida $\mathrm{em}$ termos de fixação de carbono, mas tem o inconveniente de devolver quantidades expressivas de $\mathrm{CO}_{2}$ à atmosfera a médio prazo, na medida $\mathrm{em}$ que a biomassa gerada passa a ser utilizada economicamente ou decomposta biologicamente, até atingir uma situação equilibrada, configurando uma quantidade de Carbono retida por um tempo determinado.

A energia do ciclo do hidrogênio năo emite $\mathrm{CO}_{2}$, apenas $\mathrm{H}_{2} \mathrm{O}$ e $\mathrm{NO}$. Trata-se, portanto, de um combustível ideal para controlar definitivamente o efeito estufa produzido pelo excedente de $\mathrm{CO}_{2}$ na atmosfera. Até mesmo o NOx pode ser reduzido ou eliminado como emissão, na medida em que a dissociação da água gera hidrogênio e oxigênio na exata proporção da demanda de cada um desses elementos na combustão, podendo, em determinadas circunstâncias, ser realizada com O2 puro ao invés de ar atmosférico. 


\section{Missão}

O presente estudo pretende estabelecer o dimensionamento básico da primeira das medidas apontadas, para que se produza a fixação de carbono através de um programa de megarreflorestamento no Brasil - em tamanho e condiçóes compatíveis com um esforço mundial -, do qual o programa brasileiro será uma fração da ordem de $5 \%$. Será, sobretudo, a ponta-de-lança de um processo, onde serão definidas as metodologias de concepçáo e de projetos florestais, diferenciadas regionalmente e inseridos em áreas já ocupadas do país, sem comprometer a agricultura $e$ as reservas de florestas nativas.

No Brasil intertropical, um Plano Nacional de Reflorestamento deve beneficiar sobretudo as areas de formaçōes abertas onde a agricultura ainda nōo se expandiu por grandes espaços...
O tempo disponível para a estabilizaçáo de $\mathrm{CO}_{2} \mathrm{em}$ um patamar entre os $345 \mathrm{ppm}$ atuais e $290 \mathrm{ppm}$ pré-industriais, através do reflorestamento, deverá ser consumido simultaneamente para que se produzam as transformaçōes definitivas dos processos de combustăo de energia fóssil (carváo, petróleo e gás natural) em processos brandos quanto a emissóes de $\mathrm{CO}_{2}$. As tecnologias básicas estáo desenvolvidas. Até protótipos, jă em terceira geração, de automóveis movidos a hidrogênio, existem na Europa; a Uniẳo Soviética testa um aviăo (TU-155) movido exclusivamente por hidrogênio, e na Califórnia testam-se coletores solares e geradores eólicos em grande escala. Tudo isso sinaliza para a entrada definitiva do hidrogênio na matriz energética do futuro próximo (vide Anexo C).

Por oportuna coincidência, em muitos países ou regióes produtoras de petróleo, ocorrem também os climas áridos e semi-áridos de alta insolação, como os desertos do norte da África, do sudoeste dos EUA, bem como o Nordeste do Brasil, todos eles adequados para instalaçáo de projetos de energia solar. Essa coincidência atua no sentido de mitigar os impactos que as transformaçóes do modelo energético brando em emissóes de $\mathrm{CO}_{2}$ poderiam provocar sobre a economia dos produtores de petróleo, dado que a alta capitalizaçáo das economias desses países ou regióes poderá vir a ser um fator positivo na composição do capital que deverá bancar essas grandes transformaçóes energéticas.

O megarreflorestamento destinado a reduzir o excesso de $\mathrm{CO}_{2}$ do ar somente terá sentido, do ponto de vista desse objetivo, se forem adotadas as medidas definitivas delineadas acima, ou outras, como a fusão nuclear, que venham a ser viabilizadas econômica, social e ambientalmente.

Estudos Avançados, 4(9) 


\section{Considerações preliminares sobre reflorestamento no Brasil}

Entre os problemas básicos do Brasil, neste fim de século, inclui-se um cuidado particular com o reflorestamento de áreas degradadas e o aproveitamento de espaços adequados para uma silvicultura de fins múltiplos.

De um lado, existe a preocupação com a elaboraçăo correta de uma política nacional de florestas. E de outra parte, uma busca de açóes participativas voltadas para a fixaçáo do carbono em períodos de rápida atuação e sob critérios inteligentes de organização do espaço. Tais critérios devem se pautar em propostas que não impliquem tamponamento de áreas agrícolas produtivas e nem tampouco interfiram nos programas de reconstruçáo e reafeiçoamento de setores críticos das regiōes mais afetadas, em conseqüência de sucessivos ciclos agrários direta ou indiretamente predatórios.

Baseados no balanço de sucesso/insucesso dos programas empíricos de reflorestamento subsidiados ocorridos nos últimos 20 anos, é de todo conveniente conceber um programa pan-brasileiro de reflorestamento, sob critérios técnico-científicos corretos $\mathrm{e}$, à custa de estratégias de previsão de impactos suficientemente combinados, para tornar factiveis e aceitáveis as diferentes açóes do grande plano.

O território brasileiro, considerado em sua grandiosidade espacial e na somatória dos seus setores geoecológicos, presta-se admiravelmente para um plano global de ampliação de fitomassa em áreas de cobertura vegetal aberta ou em setores de forte carga predatória dos processos agrícolas e/ou pecuários, além de que, em funçáo de seu quadro atual de uso e utilização de solos visto na escala de Sul a Norte, exige uma identificação mais criteriosa de áreas reflorestáveis, com a finalidade básica de estancar a progressão da sangria das grandes massas de vegetação natural existentes na Amazônia, ameaçadas de desmatamentos desnecessários e caóticos.

Neste sentido, tem-se plena certeza que um Plano Nacional de Reflorestamento pode refrear e conter a marcha da destruiçáo da floresta amazônica nos níveis que vem se processando.

\section{Critérios de inclusão e exclusão}

Considerando-se os quatro grandes domínios de natureza de Brasil intertropical $e$ as duas regióes naturais subtropicais, com os seus 
diferentes agrupamentos de ecossistemas, e, levando-se em conta o mosaico global de solos ocorrentes em cada uma delas, assim como as experiências prévias de silvicultura $\mathrm{e}$ as raras açóes de reflorestamento ecológico, torna-se possível identificar áreas preferenciais e regióes de exclusão criteriosa.

No Brasil intertropical, um Plano Nacional de Reflorestamento deve beneficiar sobretudo as áreas de formaçóes abertas onde a agricultura ainda não se expandiu por grandes espaços e nas quais se pode fazer uma reciclagem da pecuária por melhoria da qualidade e contenção espacial, a fim de se encontrar subespaços ponderáveis para a introduçáo organizada de florestas plantadas.

Excluem-se desse tipo de silvicultura baseada em espécies adaptadas, de crescimento rápido e grande fitomassa, as regiōes dotadas de menos de $850 \mathrm{~mm}$ de precipitações anuais, as quais em seu conjunto situam-se, principalmente, nos sertôes do Nordeste. Em relaçáo a esta grande área semi-árida do Brasil intertropical, propóe-se um subprograma particular de reenriquecimento das estreitas florestas-galerias, conhecidas por matas da c'raiba e um vigoroso processo de reflorestamento das encostas e interflúvios das colinas sertanejas por espécies do tipo do algaroba, a fim de obter um quadro de vegetação mais próxima do perenifólio por meio de uma espécie de utilizaçăo múltipla.

Quanto à Amazônia, a necessidade da sua exclusão (em termos globais ainda que náo totais) liga-se ao fato de que ela continua sendo a grande reserva em pé da América tropical que carece de medidas protetoras mais de que propriamente planos extensivos de reflorestamentos. Não há como incluir os espaços geoecológicos amazônicos, vistos em seu todo, como espaços potenciais de reflorestamento. No entanto, faixas degradadas nos arredores de grandes cidades (Belém, Manaus, Santarém, Imperatriz, Macapá, entre outras), assim como as grandes áreas pré-amazônicas pontilhadas de agropecuárias mal-sucedidas, merecem uma particular atençáo dentro do plano. Sem pretender multiplicar os Jaris, o plano abre espaço para proteger o que foi implantado e cuja experiência técnica permitirá reorientar processos racionalizados de silvicultura em faixas de desmate muito extensivo, tais como os ocorridos ao longo de setores da rodovia Belém - Brasília e mais recentemente ao longo da estrada de ferro Carajás - São Luiz, sobretudo no planalto maranhense.

É sabido que nenhum ecologista consciente deste país daria o seu aval para elaboraçáo de espaços de silvicultura locais, em detrimento da supressáo de áreas da floresta natural. Entretanto, pelo oposto, todos 
os ambientalistas esclarecidos têm consciência de que é preciso endereçar projetos de reflorestamento ecológico ou de florestas plantadas para as áreas que sofreram predaçōes irremediáveis no entorno de cidades, em trechos de solos pobres, ou em áreas de drenagem desperenizada (trechos secos).

Ao inspecionar cartas topográficas combinadas com mapas pedológicos e fitogeográficos do país visto como um todo (e baseando-nos, sobretudo, em conhecimento de campo acumulado em muitos anos de pesquisas), identificamos as grandes áreas de exclusão e nos fixamos em alguns espaços preferenciais que, pela sua topografia, natureza de solo e atual sistema de utilizaçáo, poderiam ofertar boas condiçóes para silvicultura.

Paralelamente, identificamos as áreas degradadas do Brasil tropical e subtropical, onde existe necessidade premente de programas híbridos, sobretudo ecológicos, de reposiçáo florestal.

No que diz respeito às áreas de exclusão mais contínuas, selecionamos, por critérios diferenciados: a Amazônia vista no seu conjunto; o grande Pantanal Matogrossense; e o Nordeste seco, que por sinal, originou um subprograma particular de reflorestamento pró-parte ecológico, pró-parte utilitário.

Feitas as exclusōes essenciais, levamos em consideraçáo as grandes áreas agrícolas efetivamente produtivas do país, tais como: norte do Paraná, oeste de São Paulo, porções orientais de Paraná e Santa Catarina, noroeste do Rio Grande do Sul, Recôncavo e Zona da Mata nordestina, chapadóes ocidentais de Mato Grosso do Sul e áreas agrícolas em expansão de Minas Gerais, região de Barreiras e Irecê na Bahia, entre outras, para as quais é impossível fazer proposiçóes de silvicultura extensiva. Evidentemente, sáo áreas que podem receber uma certa taxa intersticial de reflorestamento ao longo da beira de riachos e rios, em cabeceiras de drenagem, faixas escarpadas, para as quais se espera algumas modificações no sistema de exploração agrícola e até modificaçáo nos procedimentos de queimadas dos canaviais, tarefa a executar com o nível de detalhamento exigido num segundo momento do Plano Geral de Reflorestamento.

\section{Levantamento preliminar de áreas disponíveis}

A identificação de áreas para a execuçáo de um programa de reflorestamento e silvicultura, ao longo do espaço total do território 
obrigatório combinar essa ampliaçăo regional de florestas homogêneas com programas de reflorestamento de áreas ou faixas fortemente degradadas (beira-rio, cabeceiras de drenagem, grotōes, vertentes de forte declividade). Por último, prevê-se uma intensificação da cultura da árvore em qualquer tipo de gleba do Brasil, onde haja possibilidade de manter pequenos ou médios bosques, de propriedades de 10 a 5.000 hectares, para complementação do orçamento familiar dos proprietários. Identicamente pressupōe-se esse tipo de implantaçăo de bosques para qualquer setor de glebas onde foram suprimidas partes de florestas primárias e náo se encontrou uma economicidade plena através de atividades ditas agropecuárias. Através de uma boa seleção de clones, para evitar impactos ecológicos negativos, esse reflorestamento interno parcial intraglebas ou intra-setores degradados de glebas pode ajudar a recompor a diversidade orçamentária de pequenos, médios ou, até mesmo, grandes proprietários. Conforme a organização que se dê aos talhōes e faixas de plantação dos bosques no interior das glebas, poder-se-á robustecer a economia agrária e recompor a paisagem de glebas em transmudaçáo para fazendas e sítios organizados. Náo se trata, portanto, de inserir florestas homogêneas cab́ticas no interior dos espaços disponíveis de propriedades rurais e, sim, de, através de um pequeno plano que atenda as peculiaridades topográficas e edáficas de cada gleba, inserir racionalmente réstias e faixas de bosquies, com o uso de essências mais adequadas para cada regiáo.

No que tange aos reservatórios de hidrelétricas, propor um generalizado reflorestamento das margens dos lagos, segundo planos específicos para cada área em obediência às condiçóes das regiōes em que eles estejam inseridos.

\section{Identificação dos espaços escolhidos}

Estabelecidas as tipologias de espaços disponíveis e, paralelamente, os tipos de açóes de reflorestamento e/ou silvicultura recomendáveis, foi possível lançar em mapas o mosaico das áreas preferenciais para a implantaçáo de um programa consistente e viável de reposiçáo ou implantação seletiva de biomassas florestais. Para melhor visualizaçáo do conjunto das áreas, resolveu-se utilizar um mapa da vegetação da América do Sul (Hüeck e Siebert) e, em éscala mais adequada, um recente mapa da vegetaçáo do Brasil (1988), elaborado em nível de síntese, pelo somatório das pesquisas dos grupos de Botânica e Fitogeografia do Projeto RADAM (atualmente integrado ao IBGE).

No Anexo E, consta uma relaçăo dos espaços selecionados e, no Anexo 
I, uma cópia reduzida do mapa acima mencionado, sobre o qual foram indicadas as respectivas localizaçóes geográficas dos espaços escolhidos.

\section{Consideraçóes quantitativas}

O Anexo E mostra um quadro com as superfícies estimadas para cada um dos espaços selecionados, as suas respectivas taxas de ocupaçăo e os destinos visualizados para os mesmos. $O$ quadro, por apresentar muito resumidamente uma visão quantitativa de conjunto, merece ser complementado com os seguintes comentários:

- 43,5\% do total de espaços escolhidos são reservados para atividades agrárias diversificadas e para preservação de ecossistemas peculiares em faixas e setores pré-selecionados.

- Os projetos de caráter corretivo com características de descontinuidade acentuada sáo considerados áreas merecedoras de um tratamento especial (periferia sul da Amazônia e sertóes do Nordeste). Estes espaços ocupam 39\% da superfície total das áreas selecionadas.

- As atividades florestais ocupam 17,5\% dos espaços selecionados e se subdividem em: florestamentos corretivos; reflorestamentos industriais caracterizados por plantaçóes clonais, produtividade elevada, muitas das vezes à custa de adubos; reflorestamentos e/ou florestamentos mistos, nas seguintes proporçóes relativas:

Florespmento corretivo

Reflorestamento misto

Reforeamento industrial

Tomal $\left(201.480 \mathrm{~km}^{2}\right)$
$14,4 \%$

$13,8 \%$

$71,8 \%$

$100,0 \%$

As porcentagens acima apontadas demonstram uma percepçáo e uma consciência de ser necessária a incorporação de projetos de caráter essencialmente ecológico num plano de megarreflorestamento como o FLORAM. 
- As áreas com potencial de reflorestamento, totalizando 201.480 $\mathrm{km}^{2}$, representam $12,6 \%$ dos espaços selecionados, e equivalem a $2,4 \%$ do território brasileiro $\left(8,5\right.$ milhóes de $\left.\mathrm{km}^{2}\right)$; ou, aproximadamente, a $0,5 \%$ da área florestal mundial $(41,4$ milhóes de $\mathrm{km}^{2}$ ); ou, ainda, a $0,75 \%$ da superfície mundial coberta por florestas fechadas (26,6 milhōes de $\left.\mathrm{km}^{2}\right)$.

- Cabe ressaltar que os $201.480 \mathrm{~km}^{2}$ selecionados para atividades florestais específicas significam uma taxa de ocupaçăo prática de apenas $17,5 \%$ - metade da média aritmética das taxas de ocupaçáo recomendadas para as diferentes glebas selecionadas - o que permite afirmar que esta taxa de ocupaçáo prática resulta de uso de critérios de ocupação prudentemente conservadores.

- Cabe salientar também que as superfícies listadas para os espaços escolhidos são o resultado de estimativas educadas, cuja precisão é avaliada $\mathrm{em}$, aproximadamente, $10 \%$ ao redor das médias usadas nos cálculos quantitativos.

\section{Consideraçóes qualitativas}

Na maioria dos espaços considerados, a floresta constitui um comum denominador vocacional decorrente das condiçóes ecológicas predominantes. Nestes espaços, os ingredientes necessários para a fotossíntese estão presentes. Porém, em algumas regiốes de transiçăo entre o domínio dos cerrados e caatingas, se faz sentir a influência da falta sazonal de chuvas, ao ponto de tornar a água um fator ambiental limitante em maior o menor grau. As carências na composiçảo dos solos podem se constituir em fatores limitantes adicionais que contribuem para definir e dispersar os níveis de produtividade.

A literatura sobre a produtividade florestal e seus níveis registra resultados de inúmeras tentativas para captar o enorme fluxo de energia fotossintética sob a forma de estruturas moleculares na matéria orgânica, fixadoras de carbono atmosférico na fitomassa. Com base nesta literatura, foi possível elaborar estimativas para níveis de produtividade florestal $e$, visando atender as necessidades do presente estudo, foram estabelecidos arbitrariamente cinco níveis de produtividade potencial, como segue: alta, alta/média, média, média/baixa e baixa. A classificaçáo dos espaços selecionados por nível de produtividade potencial é mostrada no quadro seguinte: 
PRODUTIVIDADE POTENCIAL PARA OS ESPAÇOS SELECIONADOS

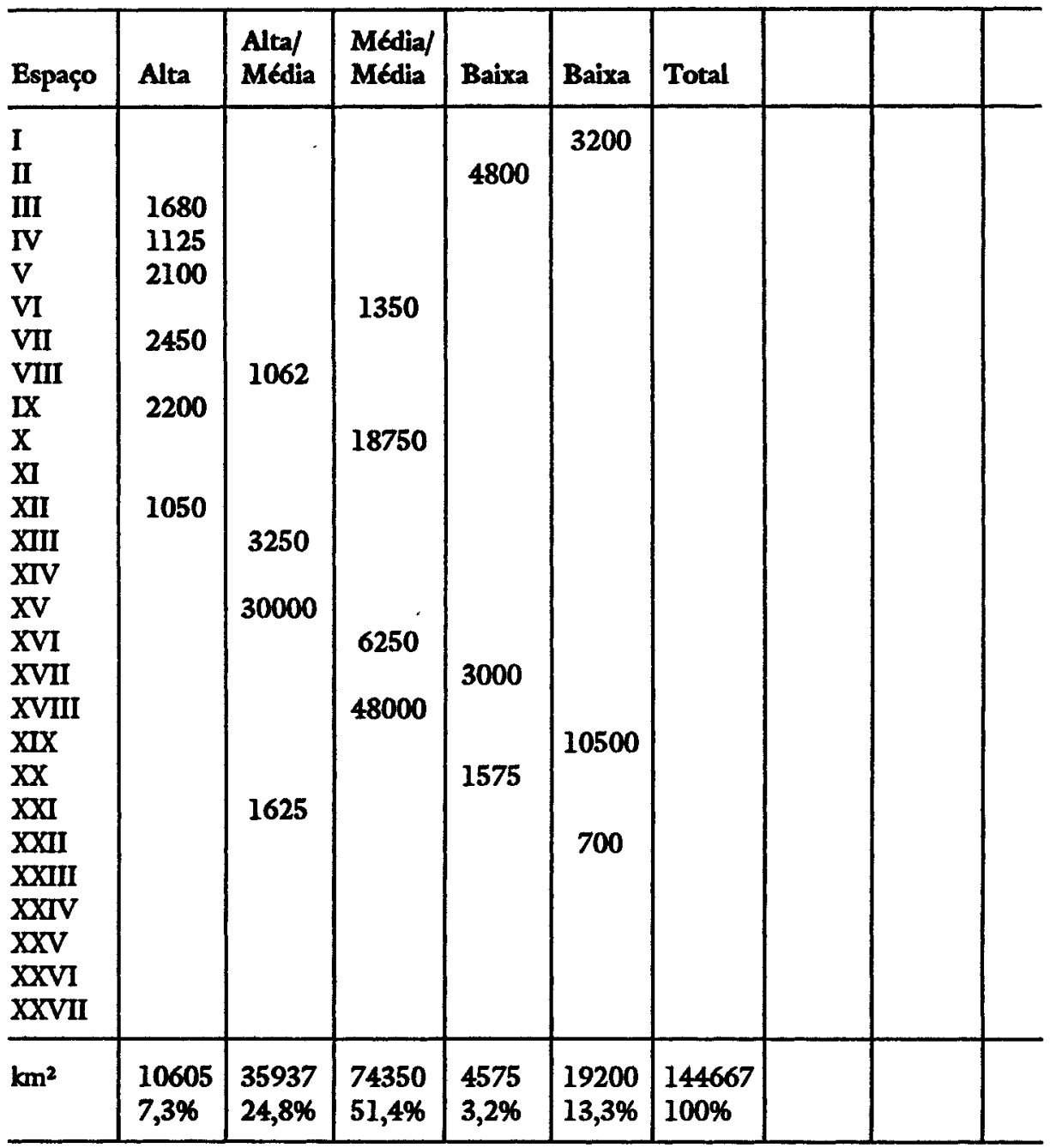

Para estes solos, foram considerados os níveis de produtividade potencial, indicados na posição 10 do quadro comparativo de produtividades florestais dos Anexos $\mathrm{G} \mathrm{e} \mathrm{H}$, como segue:

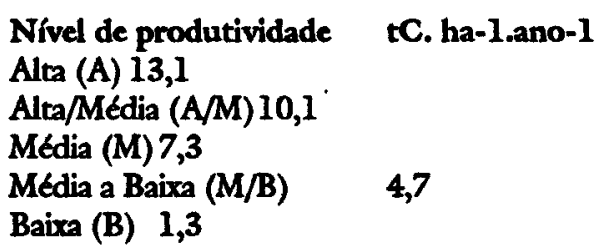

A representaçăo gráfica do Anexo $\mathrm{H}$ permite melhor visualização da convergência das médias calculadas para cada conjunto de valores relativos à produtividade de florestas situadas em diferentes latitudes do globo. Também dimensiona as estimativas de produtividade para as duas espécies mais provavelmente utilizadas nos reflorestamentos industriais (eucaliptos e pinheiros). 
A classificação acima resulta numa fixaçáo total de carbono que equivale a uma média ponderada de 7,5 tC.ha-1.ano-1 (ou 28,3 m3. ha-1.ano-1), valor que pode ser considerado razoável, com base nos dados da literatura tanto brasileira como estrangeira sobre 0 assunto (posiçáo 11 do quadro comparativo de produtividades florestais).

Como referencial adicional, na posição 12 do quadro comparativo de produtividades florestais, consta o valor de 6,3 tC.ha-l.ano-1 como uma estimativa de produtividade florestal média global. Este valor $\epsilon_{0}$ resultado de dividir a biomassa global estimada para as florestas tropicais (789 bilhóes de toneladas de matéria orgânica) pela superfície ocupada por estas florestas (1.838 milhöes de hectares), multiplicando o cociente pelo fator de conversáo 0,45 e dividindo o resultado por 34 (ou número de anos considerados necessários para atingir um valor estacionário).

Os valores de produtividade florestal utilizados neste estudo visam possibilitar a elaboraçáo de uma estimativa quantitativamente confiável da contribuiçáo brasileira ao esforço global necessário para reverter as previsóes de mudanças climáticas decorrentes do efeito estufa.

Os valores propostos se fundamentam em resultados e observaçóes publicados por diferentes autores (Anexo F) e não são outra coisa senão uma simples expressão estatística que permite prefigurar um potencial de produçáo fotossintética de certas estruturas orgânicas em determinadas condiçóes ambientais.

É sabido que uma produtividade elevada depende em grande parte da energia solar disponível para a fotossíntese e dos critérios que, embutidos no código genético do organismo vegetal, governam a utilizaçáo da energia captada pelo sistema clorofilico e sua distribuiçáo entre as diferentes funçóes fisiológicas (crescimento, diferenciaçäo, sustentaçáo, respiração e reprodução, entre outras). A produtividade também depende do nível de fertilidade do solo, ou seja, da configuraçáo físico-química decorrente de longos processos geoquímicos e meteorológicos que alteram a composiçáo rochosa inicial: ou seja, dos seis fatores de formaçáo dos solos envolvidos no processo. As condiçóes climáticas hoje prevalescentes representam a continuidade geológica da sua interaçáo modificadora sobre a geomorfologia dos grandes domínios, microrregióes e ecossistemas, fazendo sentir sua influência quantitativa e qualitativa sobre a formação de fitomassa.

Assim, os níveis de produtividade florestal, eventualmente alcançados na execuçáo do programa FLORAM, deveráo ser considerados indicadores de maior ou menor otimizaçáo inteligente do equilíbrio estabelecido entre o potencial representado pelo código genético das 
sementes ou clones selecionados para formar as florestas plantadas e o conjunto de condiçóes ecológicas do lugar escolhido para a plantaçáo num espaço ou domínio determinado.

Portanto, o nível de otimizaçáo conseguido será uma decorrência de trabalhos de pesquisa fundamental que permitam sustentar os projetos de pesquisa aplicada a serem executados, com caráter de urgência, dentro de uma sistemática de planejamento e coordenação extremamente cuidadosa, com envolvimento de especialistas em fisiologia vegetal, em biotecnologia silvicultural e na industrialização de produtos florestais.

O quadro comparativo mostra uma separaçáo das produtividades em dois grandes grupos: valores acima de 10,6 tC. há-1.ano-1 (40 m3.há-1.ano -1); e valores abaixo desta produtividade. Esta classificaçáo decorre de que os valores acima da linha divisória traçada no quadro sáo usualmente indicativos de ter sido usado fertilizante para compensar carências específicas do solo. Estas compensaçóes apresentam custos de instalaçáo que oscilam entre US\$ 400 e 1.000 por hectare plantado. As reformas ou replantios no fim dos ciclos demandam, usualmente, uma adubaçăo complementar a um custo nunca inferior a US\$ $\mathbf{1 0 0 - 2 0 0}$ por hectare.

\section{Potencial de contribuição brasileira Cálculo do carbono fixado pelo reflorestamento}

Um programa de reflorestamento com áreas de plantaçáo anuais (dimensionadas com base na superfície total disponível dividida pelo número $\mathrm{n}$ de anos considerados), no fim do último ano terá conseguido mobilizar uma área total equivalente a $\mathrm{n} 2+\mathrm{n}$ vezes a área plantada anualmente.

2

Assim, para um progrảma de reflorestamento de $\mathbf{3 0}$ anos de duração, e no desdobramento por classes de solo da área total disponível $(20,148$ $x$ 106ha), cada uma das áreas desdobradas terá uma área a ser reflorestada anualmente calculada em $1 / 30$ da parcela original. Esta área de reflorestamento anual deverá proporcionar uma utilizaçáo anual repetida ao longo dos 30 anos do programa, totalizando 465 vezes a área calculada para a plantaçáo anual.

Este total, multiplicado pela produtividade potencial estimada para a classe de solo correpondente, deverá dar a quantidade de carbono fixado ao longo dos 30 anos.

O quadro a seguir mostra o detalhe dos cálculos que permitiram identificar esta quantidade. 


\section{Estimativa de áreas por nível de produtividade}

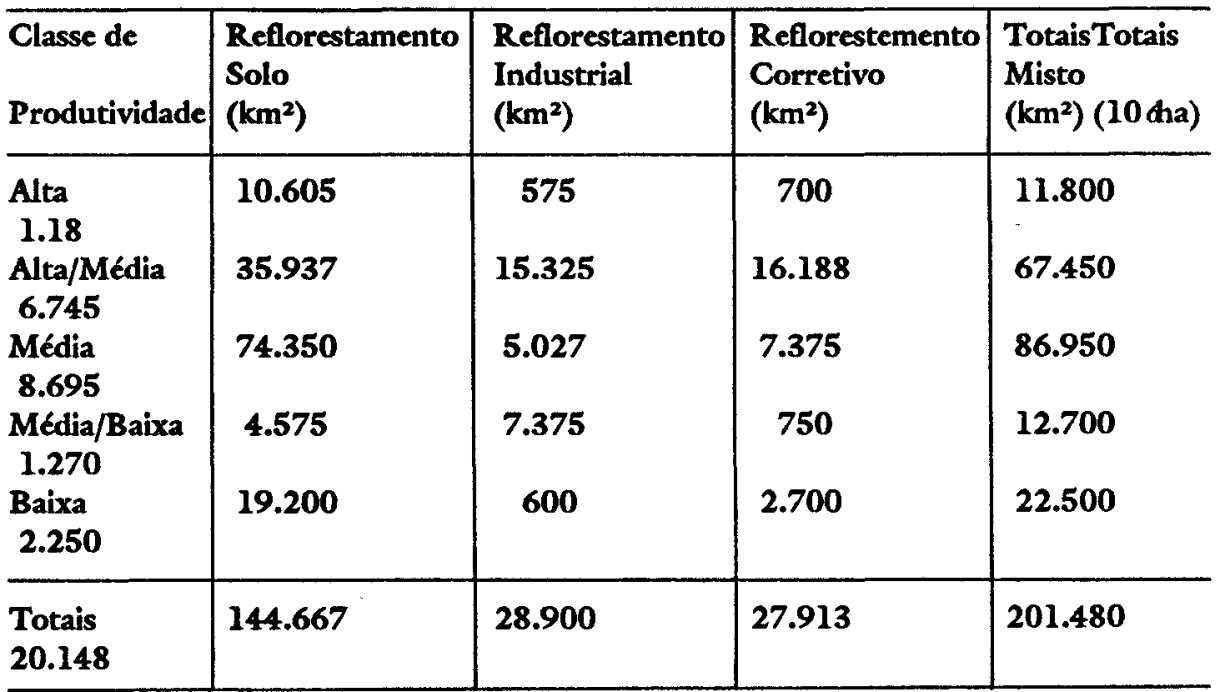

12. Estimativa de carbono fixado, por áreas de produtividade

\begin{tabular}{|c|c|c|c|c|}
\hline & $\begin{array}{l}\text { Área Plantada } \\
\text { Anualmente } \\
\text { (106ha) }\end{array}$ & $\begin{array}{l}\text { Areas Anuais } \\
\text { Acumuladas } \\
\text { (106ha) }\end{array}$ & $\begin{array}{l}\text { Produtividade } \\
\text { Potencial } \\
\text { (tC.ha-1.ano-1) }\end{array}$ & $\begin{array}{l}\text { Carbono } \\
\text { Fixado } \\
(106 \mathrm{t})\end{array}$ \\
\hline $\begin{array}{l}\text { Produtividade } \\
\text { Alta } \\
\text { Produtividade } \\
\text { Alta/Média } \\
\text { Produrividade } \\
\text { Média } \\
\text { Produtividade } \\
\text { Média/Baixa } \\
\text { Produtividade } \\
\text { Baixa }\end{array}$ & $\begin{array}{l}0,0396 \\
0,2248 \\
0,2898 \\
0.0423 \\
0,0750\end{array}$ & $\begin{array}{c}18,418 \\
104,547 \\
134,772 \\
19,685 \\
34,875\end{array}$ & $\begin{array}{r}13,1 \\
10,1 \\
7,3 \\
4,7 \\
1,3\end{array}$ & $\begin{array}{c}241,2 \\
1055,9 \\
983,8 \\
92,5 \\
45,3\end{array}$ \\
\hline Totais & 0,6715 & 312,293 & & 2418,7 \\
\hline
\end{tabular}

Carbono fixado pelas áreas de reflorestamento:

$$
2,418 \times 109+\mathrm{tC}
$$

com uma produtividade média de:

$$
\frac{2,418 \times 109 \mathrm{tC}=7,7 \mathrm{tC} \text { ha-l.ano-1 }}{312,29 \times 106 \mathrm{ha}}
$$


Além desse carbono, devemos considerar aquele fixado nos eșpaços destinados a projetos especiais visando açóes corretivas ecológicas, ou de reafeiçoamento, como resultado dos projetos especiais correspondentes. Estas parcelas adicionais de carbono foram calculadas como segue:

\section{Total de carbono fixado}

\begin{tabular}{l|ll|l|l}
\hline $\begin{array}{l}\text { Superficic } \\
\text { (106ha) } \\
\text { Espaços }\end{array}$ & $\begin{array}{l}\text { Produtividade } \\
\text { Potencial } \\
\text { (tC.ha-1.ano-1) }\end{array}$ & $\begin{array}{l}\text { Carbono } \\
\text { Fixado } \\
\text { (106t), }\end{array}$ & \\
\hline $\begin{array}{l}\text { Periferia } \\
\text { Sul-Sudeste }\end{array}$ & 15,0 & 1,32 & 306,9 & \\
$\begin{array}{l}\text { Amazonia (XVI) } \\
\text { Sertóes do }\end{array}$ & 30,0 & 1,32 & 613,8 & \\
Nordeste (XXV) & 35,0 & 2,64 & 920,7 & \\
\hline Totais & 4 & & \\
\hline
\end{tabular}

Portanto, o total de carbono fixado pela parte aérea de fitomassa será:

$$
2,418+0,920=3,338 \times 109+\mathrm{C}
$$

Se considerarmos que a parte aérea representa $2 / 3$ da fitomassa, o total fixado será:

$$
3,338 \times 1,5=5,00 \times 109 \mathrm{tC}
$$

Quantidade que representa aproximadamente $4,3 \%$ do excesso de carbono atmosférico.

\section{Benefícios decorrentes do megarreflorestamento}

Além da satisfação do objetivo ambiental maior (redução do efeito estufa) do empreendimento proposto, há que se considerar e administrar uma série de impactos que o vulto do programa poderá causar, tais como:

* Impacto sobre o balanço florestal e todas as suas conseqüências.

* Impacto econômico sobre a indústria de celulose e seus derivados pela ampliação da oferta de matéria-prima.

* Impacto sobre a construçáo civil de moradias pela oferta em abundância de madeira e derivados. 
* Impacto sobre a indústria madeireira pela oferta crescente das espécies plantadas, em detrimento de outras espécies mais tradicionais.

* Impacto energético pela oferta de matéria-prima para produção de metanol automotivo.

* Impactos ambientais decorrentes das expansóes contempladas pelas indústrias de madeira, celulose e papel.

* Impactos ecológicos relacionados com o balanço entre a monocultura

da árvore e a manutenção das biodiversidades regionais.

O programa deverá produzir diversos benefícios ligados ao meio ambiente, tais como:

* Proteção das matas nativas contra os seus predadores históricos clássicos (madeireiros, carvoeiros e lenhadores) pela oferta abundante de novas florestas.

* Preservação das florestas amazônicas, visando sua utilizaçáo contida por meio de modelos ecodesenvolvimentistas.

* Aumento do estoque de biomassa nas florestas existentes.

* Recuperaçáo de áreas de antigas florestas como medida protetora em relação a florestas nativas ainda existentes na vizinhança.

* Recuperação de áreas degradadas (solos pobres ou vertentes) mediante um uso adequado, tendo em vista a regeneraçáo do solo, e o combate à erosão e à desertificaçáo, em funçăo de alternativa econômica para a exploraçáo de tais áreas.

* Proteçáo de mananciais contra usos agrícolas inadequados, pela alternativa florestal para a cobertura de tais áreas.

* Proteçáo de Bacias Hidrográficas contra assoreamento de rios, erosōes e inundaçóes, entre outras.

* Preservaçáo de recursos hídricos.

* Regularizaçóes micro e macroclimáticas.

* Aumento e multiplicação de refúgios e estabelecimento de santuários. 
* Melhor preservaçáo da diversidade genética.

* Proteção à fauna e à flora silvestre, desde que os florestamentos sejam mistos, preservando as matas ciliares dos rios e córregos, e das escarpas e serras.

* Resgate de espécies em extinçáo, désde que inseridas nas faixas de cobertura permanentes, como matas ciliares.

* Aumento na disponibilidade de matéria-prima para intensificar a industrialização e diversificação de produtos duráveis com base florestal.

* Desenvolvimento econômico descentralizado, pelo desenvolvimento regional dos produtos florestais industrializados.

* Fortalecimento das indústrias de produtos florestais já estabelecidas regionalmente.

* Aumento das áreas de lazer.

* Melhora paisagística decorrente dos reflorestamentos urbano e rural.

* Propostas estratégicas para evitar a "aldeia global" e interromper tendências exageradas de conurbaçōes.

\section{Produtos florestais industrializados}

Pela ampla abrangência da sua possível diversificaçáo, a industrializaçáo adequada dos produtos de origem florestal se apresenta como uma sólida coluna de sustentação para um desenvolvimento social e econômico de extrema importância, pelo seu caráter fortemente indutor de atividades regionais. Este potencial de utilidade tem sido reconhecido e apontado repetidamente pelas entidades internacionais que visam identificar e recomendar os caminhos mais convenientes para promover um desenvolvimento regional e harmônico. Neste sentido, a FAO tem recentemente publicado uma série de relatórios apresentando um Plano de Açáo Florestal para os trópicos, onde são indicadas as principais vantagens que apresentam um desenvolvimento social e econômico, quando se fundamentam na silvicultura e nos múltiplos desdobramentos de industrialização das matérias-primas conseguidas das florestas.

Pela sua diversidade e versatilidade, a industrializaçáo dos produtos florestais pode se apresentar na forma de sucessivas cascatas 
representando estágios de processamento artesanais que demandam pequenas ou médias empresas (dependendo do nível de independência ou verticalização), que podemos imaginar situadas no extremo de um leque amplamente aberto, em cujo outro extremo se situam indústrias de grande porte com demandas elevadas de investimentos e incorporando uma utilização intensiva de tecnologias de ponta nos seus processos de transformação.

As atividades ligadas ao reflorestamento e aos processos de beneficiamento e industrializaçáo dos produtos e subprodutos florestais se constituem numa poderosa alavanca indutora de um desenvolvimento social e econômico que atende, pela sua flexibilidadé, às características mais diversas e diferenciadas que prevalecem nos éśaçós considerados neste documento.

Um excelente exemplo dessa flexibilidade pode ser observado no Estado de São Paulo, onde a silvicultura se apresenta em duas áreas bem diferenciadas pelo seu estilo de aproveitamento florestal separadas por uma linha imaginária aproximada, com orientaçáo $S E-N W$. As áreas situadas ao $\mathbf{N}-\mathrm{E}$ dessa linha sáo representativas de atividades silviculturais mais de acordo com a mentalidade rural, no que diz respeito ao aproveitamento econômico de uma biodiversidade natural, que conta com os benefícios de uma proteçăo fitossanitária de caráter orgânico. Ao $S-W$ da divisória, situam-se áreas que incorporam uma perspectiva industrial dentro do seu enfoque agrícola e, portanto, expressam uma vocação de grandés glebas paśsíveis de exploração a uma escala convidativa para grandes empresas. Essas áreas demandam investimentos elevados, utilizaçáo de tecnologias de ponta e uma planificação e monitoração cuidadosa e detalhada das atividades nécessárias para assegurar um nível elevadó de produtividade para 0 : empreendimento. Esses níveis de produtividade usualmente só podem ser atingidos mediante plantaçóes clonais diferenciadas, cuidadosamente selecionadas e cuja proteção fitossanitária deve ser adequadamente arquitetada com caráter preventivo. A uniformidade dos produtos florestais obtidos nas áreas "novas" e a maior segurança na continuidade das suas características permitem conseguir valores agregados mais elevados, assim compensando amplamente os investimentos adicionais demandados pelo controle e monitoração do desenvolvimento da fitomassa, pelas atividades de $P+D$, e pelas necessárias complementaçóes de nutrientes e fertilizantes, investimentos estes bern mais elevados na silvicultura moderna do que nos reflorestamentos tradicionáis.

Por oportuno, cabe lembrar, neste ponto, que a consecuçăo de valores elevados de produtividade é o resultado de longos trabalhos de 
pesquisa multidisciplinar (biotecnologia silvicultural, fisiologia botânica, solos, entre outras áreas), demandando recursos humanos altamente especializados e escassos, por ser sua formaçáo um processo que demanda um longo tempo de maturação e uma forte e persistente vocação inicial.

Assim sendo, a mobilização destes recursos humànos configura investimentos adicionais por hectare de reflorestamento que náo podem ser esquecidos, porquanto uma carência destes recursos pode se constituir em fator limitante para o programa.

Assim, os dois estilos de reflorestamento exemplificam as duas posiçóes extremas num leque amplo e aberto de estilos de reflorestamento opcionais, em cuja parte central,está se visualizando o aparecimento de novas opçóes decorrentes de interaçóes positivas entre os dois estilos extremos. Assim, o estilo tradicional estaria internalizando os benefícios das biotecnologias de ponta que se demonstraram eficazes nas técnicas de reflorestamento mais modernas.

Nesse contexto, cabe mencionar a opçáo cooperativista e seu potencial de atendimento de eventuais exigências decorrentes de uma escala operacional dilatada, em áreas tradicionais, contornando o risco de aumentar a concentração da propriedade das terras.

\section{Conclusões preliminares}

Espelhando uma preocupaçäo pelos problemas ecológicos de caráter global, e respeitando as características ecológicas regionais, foram identificados um total de $201.000 \mathrm{~km}^{2}$ potencialmente acolhedores de atividades florestais, onde $144.000 \mathrm{Km}^{2}$ seriam destinados a reflorestamentos industriais propriamente ditos.

A escolha e seleçáo de espaços precisou transpor um labirinto de condiçōes regionais $\mathbf{e}$ inter-regionais as mais diversas $\mathbf{e}$ heterogêneas que demandaram a identificação, a grandes traços, das soluçōes e encaminhamentos específicos para cada regiáo.

A complexidade do mosaico dos espaços selecionados tornará imperativa uma monitoraçáo executiva mediante imagens obtidas por sensoreamento remoto, visando atingir condiçóes adequadas de eficiência e confiabilidade. Permite, também, antever a conveniência de se institucionalizar açōes de caráter informativo, de assessoria e complementação tecnológica, de irradiação essencialmente regional em centros localizados estrategicamente. 


\section{INVENTÁRIO GLOBAL DO CARBONO \\ CARBONO NA FITOMASSA CONTINENTAL}

Em decomposição (Humus)

$1.000-3.000$

Florestas, vegetais vivos

$600-830$

Total continental

$1.600-3.830$

(combustíveis, fósseis: 10.000)

CARBONO NOS GASES DA ATMOSFERA

No anídrido carbônico $\mathrm{CO} 2$

$$
640-700
$$

\section{FITOMASSA OCEÂNICA}

Nas camadas superficiais

Em decomposição

Viva

Carbonatos e bicarbonatos

Nas camadas profundas

Matéria orgânica

Carbonatos e bicarbonatos

Total oceânico

Total global

44.665

$44.190-46.500$

\section{ANEXO B}

\section{MASSA DE CARBONO A SER FIXADA GLOBALMENTE}

Cálculo:

- Concentração de $\mathrm{CO}_{2}$ presente (1988):

346ppm

- Nível de CO2 considerado aceíŕvel: (nível pré-industrial)

292ppm

- Redução a ser conseguida:

54ppm

\section{Equivalência:}

$1 \mathrm{ppm} \mathrm{CO2} \quad 2,130 \mathrm{GtC}=2,130 \times 109 \mathrm{t} \mathrm{C}$

(U.S. Department of Energy, Carbon Dioxide Information Center, ORNL/CD IC-10, P.24)

Portanto, 54 ppm equivalem a:

$$
54 \times 2,13=115 \times 109 \mathrm{tC}, \text { ou }
$$

massa de carbono a ser fixada globalmente. 


\section{ANEXO C \\ HIDROGÊNIO PARA FINS ENERGÉTICOS}

As pesquisas em instalaçóes-piloto no campo do hidrogênio para fins energéticos caminham no sentido de se compensar as diferenças entre os picos de produçáo solarelétrica e de demạnda, através do armazenamento de $\mathrm{H}_{2} \mathrm{e} \mathrm{O}_{2}$, produzidos por eletrólise da água durante o excesso de insolação, para serem reconvertidos em eletricidade por processo reverso durante os picos de demanda. São significativas as pesquisas que se realizam com esse objetivo em "Neunburg vorm Wald", no Estado de Bayern (RFA), através de uma instalaçáo-piloto de $500 \mathrm{kw}$ com $5.000 \mathrm{~m}^{2}$ de células solares de diversas tecnologias, a um custo de 60 milhöes de DM (32 milhōes de US), repartidos entre o governo do Estado de Bavária (60\%) e quatro empresas privadas (BMW, MBB, Linde e Siemens), cada uma com $10 \%$.

Com objetivos semelhantes, opera a instalaçāo-piloto de 200 mégawatts, implantada no deserto de Mogave, na Califórnia, pela firma Luz Internacional Lrda.

A estimativa de custo da energia da pesquisa alemã é de 1 DM (1,85 US) por kwh de energia fotovoltaica ou de 15 DM $(8,10$ US) por equivalente energético de um litro de bleo combustível. Esses números sinalizam para um aumento dos preços da energia de ordem de 12 a 15 vezes, o que provocará um impacto semelhante ao ocorrido no mercado através dos sucessivos choques da OPEP em 73 e 79, quando o petróleo subiu de 2 US a 35 US por barril. A diferença agora será apenas a previsibilidade dos aumentos, derivados de uma transformaçáo necessária, previamente cronogramada, ao contrário dos choques da OPEP, praticados subitamente em decorrência de decisóes de cartel. 


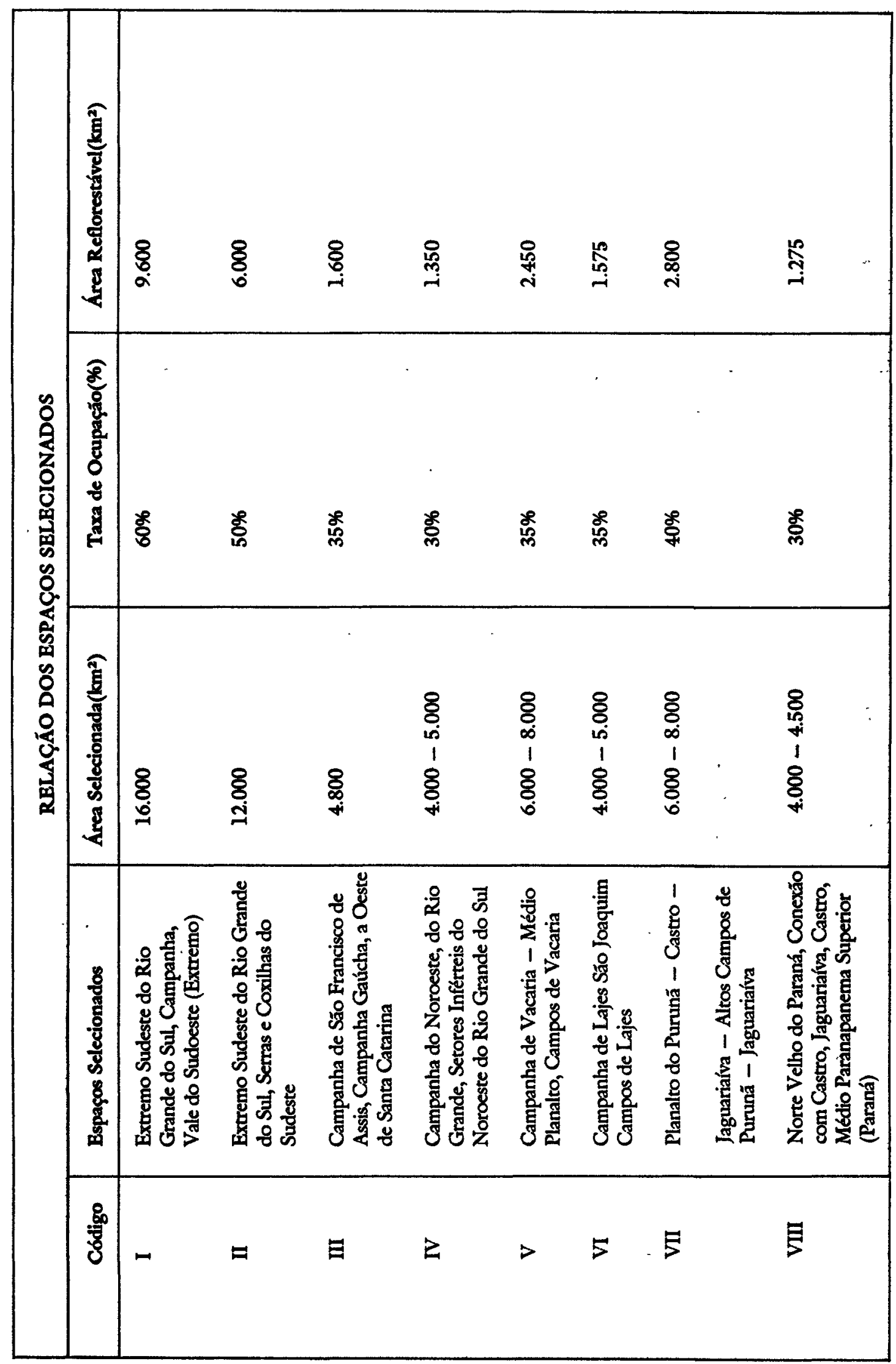

Estudos Avançados, 4(9) 


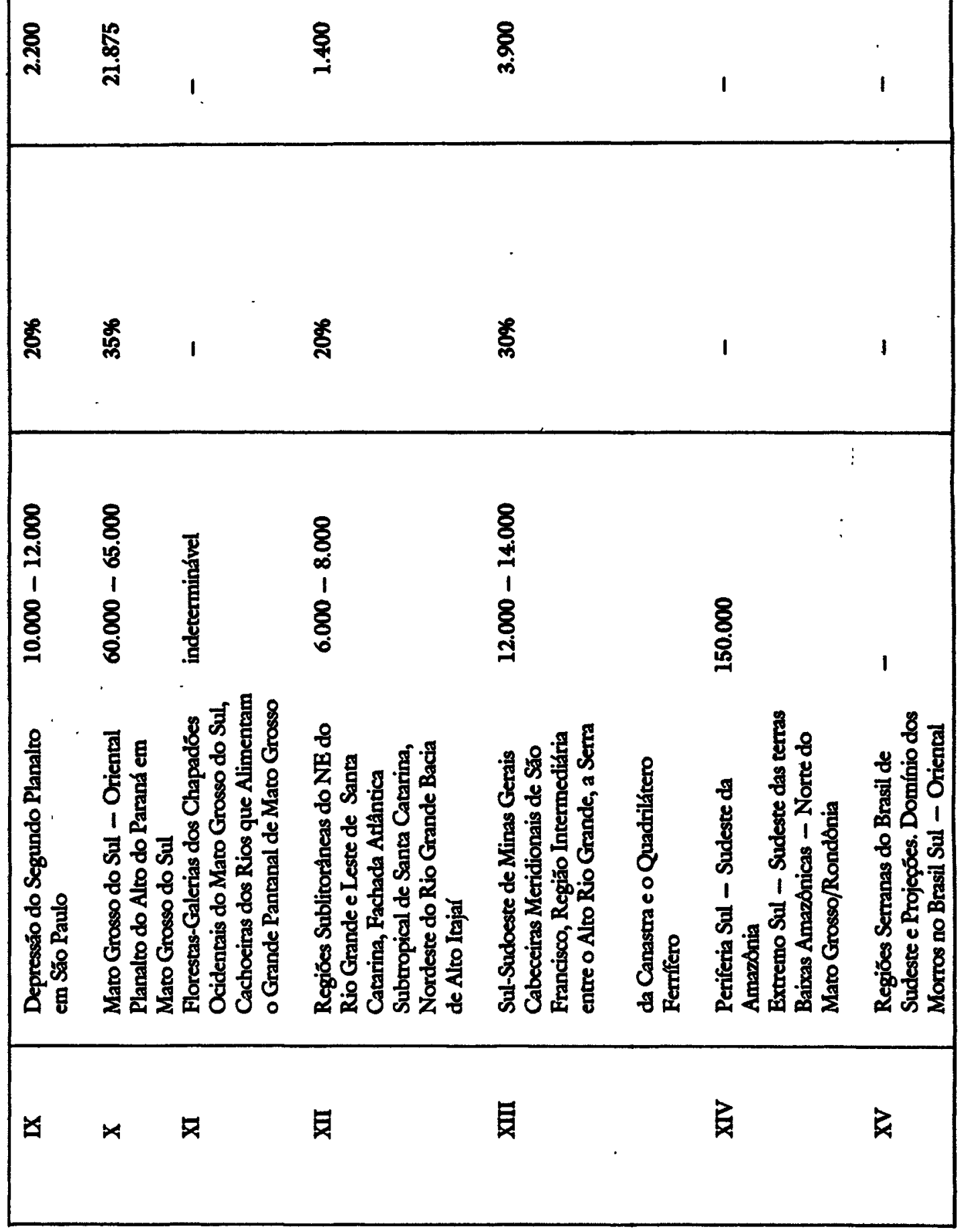




\begin{tabular}{|c|c|c|c|c|c|c|}
\hline 总 & $\begin{array}{l}8 \\
\stackrel{8}{*} \\
+\end{array}$ & $\begin{array}{l}8 \\
\text { ष्ठ } \\
\text { in }\end{array}$ & 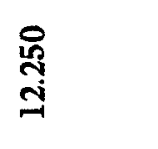 & ષ્ષે & 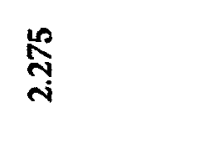 & 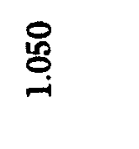 \\
\hline : & 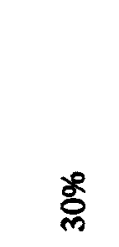 & 总 & 总 & 苛 & 总 & ఫ్ల \\
\hline 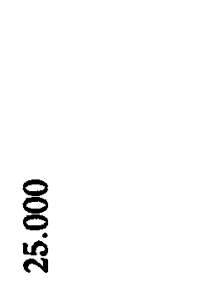 & \&్రి & $\begin{array}{l}8 \\
0 \\
0 \\
1 \\
1 \\
8 \\
0 \\
000 \\
0.0\end{array}$ & $\begin{array}{l}8 \\
0 \\
0+9 \\
1 \\
1 \\
8 \\
0 \\
0\end{array}$ & $\begin{array}{l}8 \\
8 \\
10 \\
1 \\
8 \\
8 \\
+\end{array}$ & $\begin{array}{l}8 \\
0 \\
1 \\
1 \\
8 \\
8 \\
0 \\
0\end{array}$ & $\begin{array}{l}8 \\
8 \\
+ \\
1 \\
8 \\
0 \\
i\end{array}$ \\
\hline 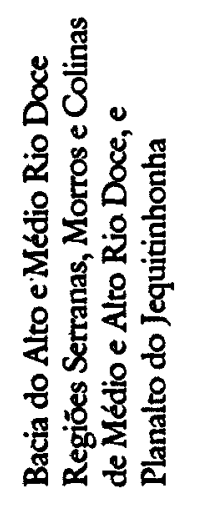 & 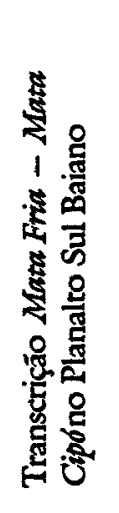 & 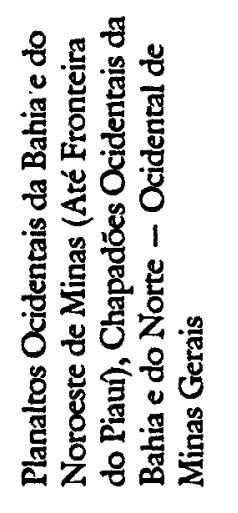 & 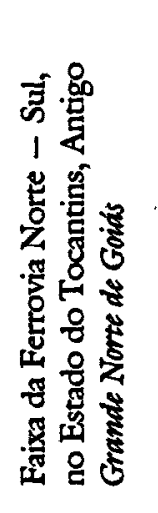 & 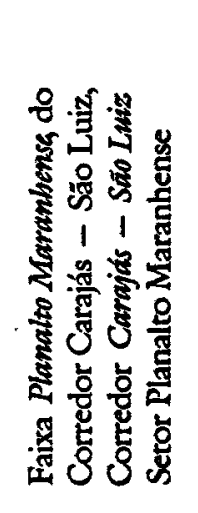 & 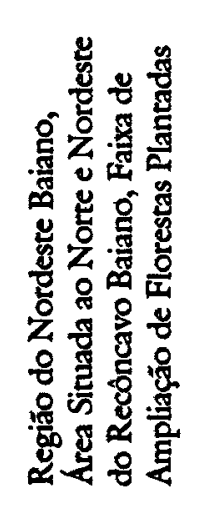 & 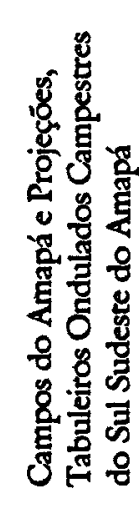 \\
\hline$\sum_{x}^{5}$ & 蛋 & 塄 & 茨 & 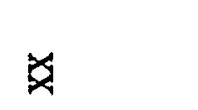 & 苋 & 㹸 \\
\hline
\end{tabular}




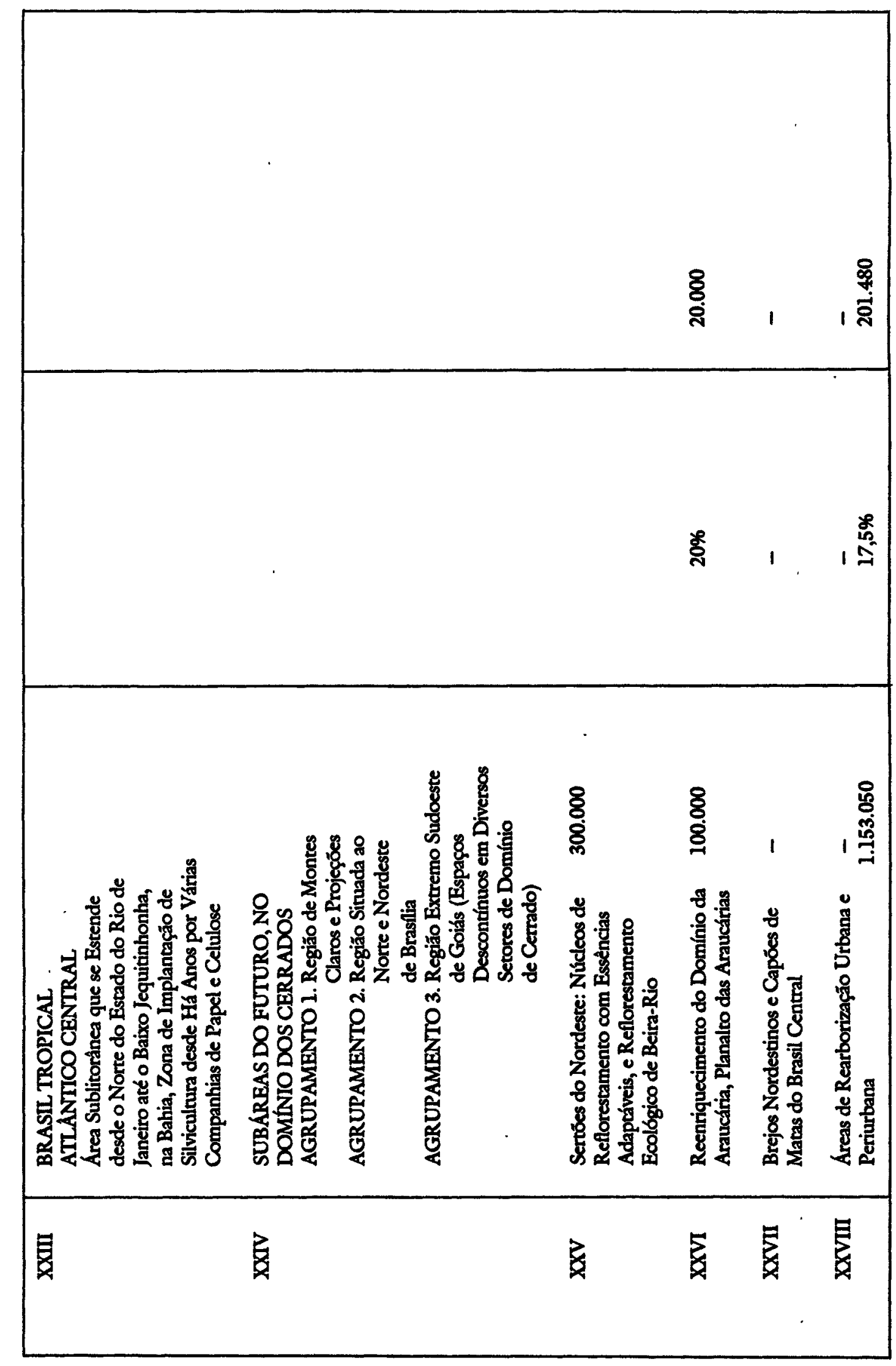




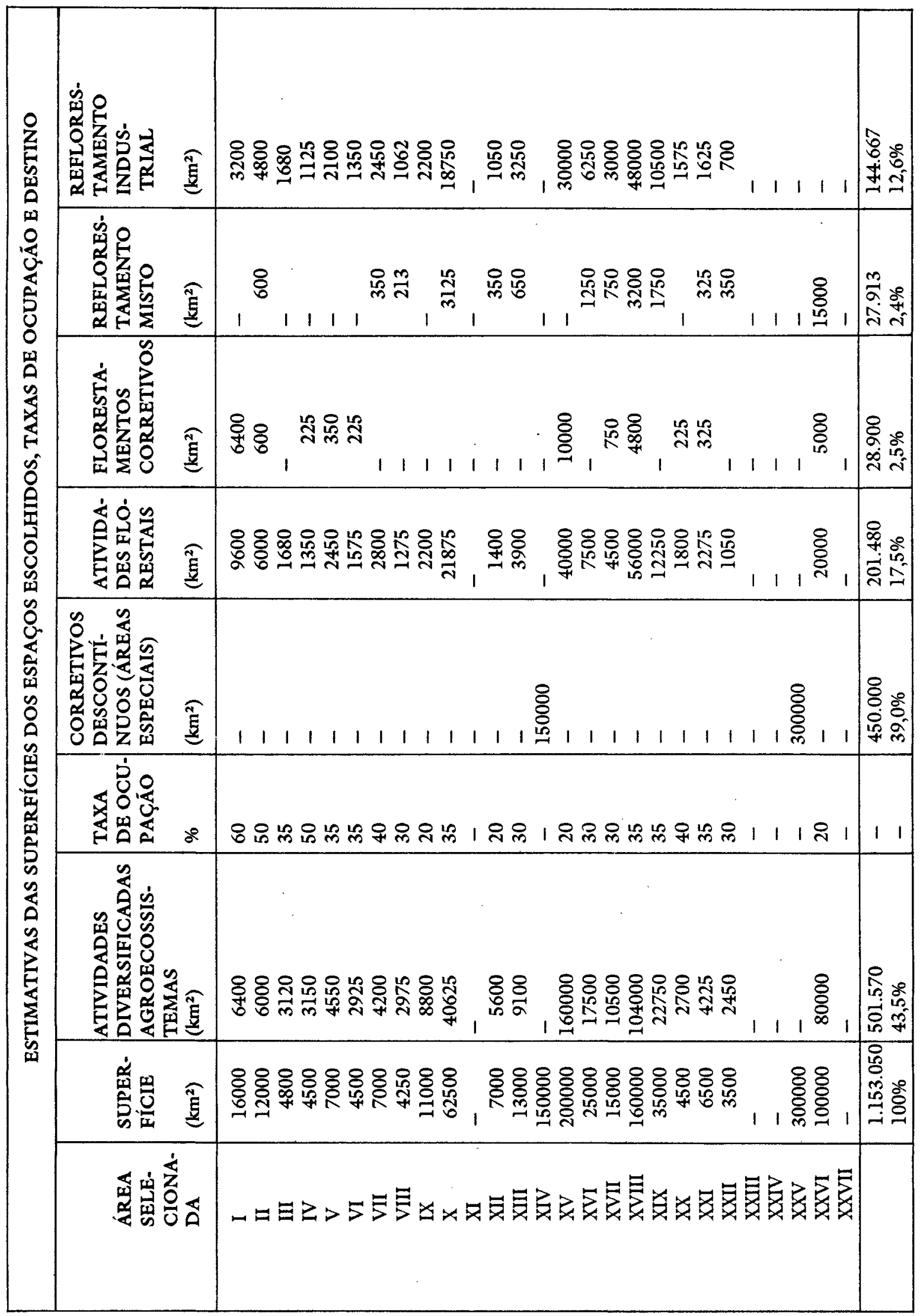




\begin{tabular}{|c|c|c|c|c|}
\hline \multicolumn{5}{|c|}{$\begin{array}{l}\text { LISTAGEM DOS VALORES UTILIZADOS NO } \\
\text { LEVANTAMENTO DE PRODUTIVIDADE } \\
\end{array}$} \\
\hline ESPÉCIE & LOCALIDADE & FONTE & $\begin{array}{l}\text { PROI } \\
\text { VIDA } \\
\text { tC.ha }\end{array}$ & $\begin{array}{l}\text { DUT- } \\
\text { DE } \\
1 \text { ano-1 }\end{array}$ \\
\hline E. globulus & Espanha & FAO-81 & 0,2 & (mín.) \\
\hline E. occidentalis & Itália & FAO-81 & 0,26 & (mín.) \\
\hline P. caribae & Caribe $(n=13)$ & LAMB-73 & 0,63 & (mín.) \\
\hline E. camandulensis & Marrocos & FAO-81 & 0,79 & (mín.) \\
\hline E. globulus & Portugal & FAO-81 & 0,79 & (mín.) \\
\hline E. grandis & BR & FAO-81 & 1,06 & (mín.) \\
\hline P. patula & Uganda & ANON-76 & 1,13 & (mín.) \\
\hline P. patula & Kenya & ANON-76 & 1,13 & (mín.) \\
\hline Picea abies & Europa & SEDJO-84 & 1,32 & \\
\hline E. grandis & $\mathrm{BR}$ & EVANS-82 & 1,32 & \\
\hline E. occidentalis & Itália & FAO-81 & 1,59 & (máx.) \\
\hline E. microtheca & Sudāo & FAO-81 & 1,85 & (mín.) \\
\hline P. caribaea & Venezuela & HELVELDOP-77 & 1,89 & (mín.) \\
\hline Gmelina arborea & Malawi & LAMB- 68 & 1,91 & (mín.) \\
\hline Gmelina arborea & Sierra Leone & LAMB-68 & 2,17 & (mín.) \\
\hline P. caribaea & Venezuela & HEUVELDOP-77 & 2,21 & $(x)$ \\
\hline Pinheiro & BR-N.Bahia & BARRICHELO-89 & 2,25 & \\
\hline Floresta tropical & & GOLLEY-72 & 2,34 & \\
\hline Gmelina arborea & Sierra Leone & LAMB-68 & 2,48 & $(x)$ \\
\hline P. caribea & Venezuela & HEUVELDOP & 2,52 & (máx.) \\
\hline E. camandulensis & Marrocos & FAO-81 & 2,65 & (máx.) \\
\hline Pasto & Temperado & WHITTAKER-72 & 2,70 & \\
\hline Gmelina arborea & Sierra Leone & LAMB-68 & 2,8 & (máx.) \\
\hline P. taeda & USA & SEDJO-84 & 3,15 & \\
\hline Florestás & Valor Médio & BRYANT-88 & 3,18 & \\
\hline Cerrados(e)capoeiras & Valor Médio & WHITTAKER-73 & 3,20 & \\
\hline P. patula & Uganda & ANON-76 & 3,38 & $(\mathrm{x})$ \\
\hline Pseudotsuga menziesii & USA & SEDJO-84 & 3,38 & \\
\hline P. patula & Kenya & ANON-76 & 3,38 & $(x)$ \\
\hline E. grandis & Afr.do Sul & FAO-81 & 3,44 & (mín.) \\
\hline Floresta Boreal & Valor Médio & LUGO-73 & 3,60 & \\
\hline Floresta Boreal & Valor Médio & WHITTAKER-73 & 3,60 & \\
\hline E. grandis & Uganda & FAO-81 & 3,70 & (mín.) \\
\hline P. caribaea & Ásia & SEDJO-84 & 3,71 & \\
\hline Gmelina arborea & Malawi & LAMB-68 & 3,83 & $(x)$ \\
\hline E. globulus & India & FAO-81 & 3,97 & (mín.) \\
\hline Gmelina sp. & Senegal & SEDJO-84 & 3,98 & \\
\hline Eucalipto & S.Fco.(MG) & BARRICHELO-89 & 4,05 & \\
\hline Savanna & Valor Médio & WHITTAKER-73 & 4,10 & \\
\hline P. patula & Áfr.do Sul & SEDJO-84 & 4,24 & \\
\hline P. caribaea & BR (AM) & SEDJO-84 & 4,24 & \\
\hline Floresta folhosa & Temperada & JORDAN-83 & 4,44 & \\
\hline Eucalipto & Média BR & ANDPC-88 & 4,50 & \\
\hline Floresta tropical & Valor Mínimo & WHITTAKER-75 & 4,50 & \\
\hline Eucalipto & Senegal & SEDJO-84 & 4,50 & \\
\hline Floresta tropical & Valor Mínimo & WADSWORTH-60 & 4,54 & \\
\hline $\begin{array}{l}\text { Fibra longa } \\
\text { E. clocziana }\end{array}$ & $\begin{array}{l}\text { Mín. BR. } \\
\text { Zâmbia }\end{array}$ & $\begin{array}{l}\text { GPEF-82 } \\
\text { FAO-81 }\end{array}$ & $\begin{array}{l}4,60 \\
4,76\end{array}$ & \\
\hline E. microconys & BR & PRODEPEF-77 & 4,76 & \\
\hline
\end{tabular}




\begin{tabular}{|c|c|c|c|c|}
\hline Gmelina arborea & $\mathrm{BR}(\mathrm{AM})$ & SEDJO-84 & 4,77 & \\
\hline Floresta tropical & Valor Mínimo & BROWN-82 & 4,82 & \\
\hline P. caribaea & Puerto Rico & LIEGER-76 & 4,95 & \\
\hline Pinheiro & $\mathrm{BR}(\mathrm{SP})$ & BARRICHELO-89 & 4,95 & \\
\hline Flor úmida & Subtropical & LUGO-78 & 4,95 & \\
\hline Flor úmida & Tropical & MULLER-65 & 5,00 & \\
\hline P. radiata & Austrália & SEDJO-84 & 5,30 & \\
\hline P. taeda & BR (Sul) & SEDJO-84 & 5,30 & \\
\hline Flor. caducifolia & Temperada & WHITTAKER-73 & 5,40 & \\
\hline Flor. perene & Temperada & WITTAKER-73 & 5,40 & \\
\hline Eucalipto & BR (MG) & BARRICHELO-89 & 5,40 & \\
\hline Fibra curta & BR (Míni) & GPEF-82 & 5,40 & \\
\hline Pinheiro & BR (PR,SC,RS) & BARRICHELO-89 & 5,40 & \\
\hline P. patula & Kenya & ANON-76 & 5,62 & (máx.) \\
\hline Floresta folhosa & Boreal & JORDAN-83 & 5,62 & $(x)$ \\
\hline P. patula & Uganda & ANON-76 & 5,62 & (máx.) \\
\hline Floresta úmida & Tropical & MALAISSE-81 & 5.67 & \\
\hline Gmelina arborea & Malawi & LAMB- 68 & 5,75 & (máx.) \\
\hline Floresta úmida & Tropical & HUTTER-75 & 5,81 & \\
\hline Florestas & Temperadas & LUGO-73 & 5,85 & (méd.) \\
\hline P. radiata & Chile & SEDJO-84 & 5,83 & \\
\hline Floresta folhosa & Temperada & JORDAN-83 & 6,06 & (máx.) \\
\hline E. microtheca & Sudắo & FAO-81 & 6,09 & (máx.) \\
\hline Floresta folhosa & Subtropical & JORDAN-83 & 6,31 & (méd.) \\
\hline Floresta úmida & Tropical & JORDAN-80 & 6,48 & \\
\hline Floresta úmida & $\begin{array}{l}\text { Tropical } \\
\text { Pré-montana }\end{array}$ & HUTTEL-75 & 6,57 & \\
\hline P. radiata & N. Zelândia & SEDJO-84 & 6,63 & \\
\hline E. saligna & $\mathrm{BR}$. & PRODEPEF-77 & 6,75 & \\
\hline E. resinífera & BR. & PRODEPEF-77 & 6,77 & \\
\hline Fibra longa & BR. max. & GPEF-82 & 6,80 & \\
\hline E. robusta & BR & PRODEPEF-77 & 6,88 & \\
\hline Floresta úmida & Subtropical & BANDHU-73 & 6,89 & \\
\hline Eucalipto & BR(ES) 1984 & BRANDĀO-84 & 6,90 & \\
\hline Eucalipto & $\mathrm{BR}(\mathrm{MG})$ & BARRICHELO-89 & 7,20 & \\
\hline Floresta úmida & Tropical & HUTTER-75 & 7,25 & \\
\hline P.caribaea var.hond. & BR (SP) Agudos & BARRICHELO-89 & 7,42 & \\
\hline Floresta folhosa & Tropical & JORDAN-83 & 7,62 & (méd.) \\
\hline E. grandis & Portugal & FAO-81 & 7,67 & \\
\hline Eucalipto & BR (23 exper.) & EMBRAPA-80 & 7,80 & $(x)$ \\
\hline E. urophylla & BR & PRODEPEF-77 & 7,94 & \\
\hline Flor. folhosa & Boreal & JORDAN-83 & 8,01 & (máx.) \\
\hline Fibra curta & BR (máx.) & GPEF-82 & 8,05 & \\
\hline Eụcalipto & BR (N.Bahia) & BARRICHELO-89 & 8,10 & \\
\hline Eucalipto & BR (PR,SC,RS) & BARRICHELO-89 & 8,10 & \\
\hline Floresta úmida & Tropical & KIRA-78 & 8,19 & \\
\hline Eucalipto & BR (15 exper.) & EMBRAPA-80 & 8,20 & $(\mathrm{x})$ \\
\hline P. caribaea & Caribe( 13 países) & LAMB-73 & 8,28 & $(\mathrm{x})$ \\
\hline Floresta folhosa & Subtropical & JORDAN-83 & 8,34 & (máx.) \\
\hline Floresta úmida & Tropical & KIRA-67 & 8,69 & \\
\hline Eucalipto & BR(ES) 1984 & BRANDĀO-84 & 8,70 & $(x)$ \\
\hline E. globulus & India & FAO-81 & 8,73 & (máx.) \\
\hline Eucalipto & BR(S.Bahia) & BARRICHELO-89 & 9,00 & \\
\hline
\end{tabular}




\begin{tabular}{|c|c|c|c|c|}
\hline Eucalipto & BR (SP) & BARRICHELO-89 & 9,00 & \\
\hline P. caribaea & Puerto Rico & LIEGEL-76 & 9,11 & $(x)$ \\
\hline E. grandis & BR (ES) & CAMPINHOS-74 & $.9,26$ & \\
\hline Floresta úmida & $\begin{array}{l}\text { Tropical } \\
\text { Pré-montana }\end{array}$ & NYE-61 & 9,36 & \\
\hline Floresta i & Tropical & LUGO-73 & 9,72 & (méd.) \\
\hline Floresta úmida & Tropical & WHITTAKER-73 & 9,90 & \\
\hline E. globulus & Portugal & FAO-81 & 10,05 & (máx.) \\
\hline Floresta folhosa & Tropical & JORDAN-83 & 10,48 & (máx.) \\
\hline E. grandis & BR & PRODEPEF-77 & 10,48 & \\
\hline Florestas & Rend.Elev. & BRYANT-88 & 10,58 & \\
\hline E. saligna & BR & FONSECA-79 & 10,58 & \\
\hline Floresta tropical & Valor médio & MURPHY-75 & 10,80 & $(x)$ \\
\hline E. propinqua & BR & SIMŌES-80 & 11,38 & \\
\hline Florestas tropicais & Valor médio & GOLLEY-72 & 11,39 & $(x)$ \\
\hline E. globulus & Espanha & FAO-81 & 11,64 & (máx.) \\
\hline Florestas Tropicais & Mínimo & WESTLAKE-63 & 11,70 & (mín.) \\
\hline Eucalipto & BR(19 exper.) & CAMPINHOS-80 & 12,00 & (mín.) \\
\hline Floresta Tropical & Valor Mín. & RODIN-67 & 12,15 & (mín.) \\
\hline E. grandis & Afr. do Sul & FAO-81 & 12,17 & (máx.) \\
\hline Floresta Tropical & Valor médio & WADSWORTH-60 & 12,32 & $(x)$ \\
\hline E. grandis & Uganda & FAO-81 & 13,23 & (máx.) \\
\hline Eucalipto & $\mathbf{B R}$ & ANFPC-88 & 13,23 & \\
\hline Eucalipto sp & BR & MELLO-77 & 13,2 & \\
\hline P. caribaea & Puerto Rico & LIEGEL-76 & 13,28 & (máx.) \\
\hline E. urophylla & BR & SIMÕES-80 & 13,49 & \\
\hline Brejo pântanos & Valor médio & WHITTAKER-73 & 13,50 & \\
\hline Eucalipto & BR(ES) 1984 & BRANDĀO-84 & 14,00 & (máx.) \\
\hline Floresta tropical & Valor médio & BROWN-82 & 14,21 & (x) \\
\hline Eucalipto & BR(ES) 1984 & BRANDĀO-84 & 14,30 & (mín.) \\
\hline Floresta tropical & Sarawak & MURPHY-75 & 14,45 & (máx.) \\
\hline E. grandis & BR & SIMŌES & 14,55 & \\
\hline E. grandis & BR & FAO-81 & 14,82 & (máx.) \\
\hline Eucalipto & BR(19 exper.) & CAMPINHOS-80 & 14,91 & $(x)$ \\
\hline E. grandis & $\mathrm{BR}(1967)$ & FERREIRA-83 & 3,97 & \\
\hline Floresta tropical & Valor máx. & RODNN-67 & 15,53 & (máx.) \\
\hline Floresta tropical & Valor máx. & WHITTAKER & 15,75 & (máx.) \\
\hline E. grandis & BR & FERREIRA-83 & 17,05 & \\
\hline Eucalipto & BR(ES) 1984 & BRANDÁO-84 & 18,60 & $(x)$ \\
\hline E. viminalis & BR & FONSECA-79 & 19,85 & \\
\hline E. grandis & BR(RJ)Resende & KAGEYAMA-80 & 19,85 & \\
\hline Floresta Tropical & Valor máximo & BROWN-82 & 20,00 & (máx.) \\
\hline E. grandis & BR.Tec.Silvic. & FERREIRA-83 & 21,00 & \\
\hline Floresta tropical & Valor max. & GOLLEY-72 & 21,78 & (máx.) \\
\hline Eucalipto & BR (19 exp.) & CAMPINHOS-80 & 22,20 & (máx.) \\
\hline F. caribaea & Caribe(13 paises) & LAMB-73 & 23,04 & $(x)$ \\
\hline Floresta tropical & Valor médio & MURPHY-77 & 23,22 & $(x)$ \\
\hline Floresta tropical & Valor máximo & WESTLAKE-63 & 23,40 & (máx.) \\
\hline Floresta tropical & Valor mín. & BRÜNIG-69 & 25,20 & (mín.) \\
\hline Eucaliptos sp & BR.Centro Sul & SEDJO-84 & 26,40 & \\
\hline Floresta tropical & Valor máx. & WADSWORTH-60 & 26,57 & (máx.) \\
\hline Eucalipto & BR(ES) 1984 & BRANDÃO-84 & 29,90 & (máx.) \\
\hline E. grandis & BR.proc.selec. & FERREIRA-83 & 40,00 & \\
\hline Flor.tropical & Valor máx. & BRÜNIG-69 & 40,05 & (máx.) \\
\hline
\end{tabular}




\section{ANEXO G}

PRODUTIVIDADE FLORESTAL (TC.HA-1 ANO-1)

(Tabela de Valores) (Revisão 21.02.90)

1. Florestas Tropicais

$\mathbf{X}$

Valor Máximo Valor Mínimo

$\mathbf{N}$

2. Flor. Subtropicais

$11.6 \quad 26.6$

$6.6 \quad 8.3$

3. Flor. Temperadas

$5.4 \quad 6.1$

4. Flor. Boreais

$5.2 \quad 8.0$

5. Florestas Diversas

$9.8 \quad 26.6$

6. Eucalipto - Brasil

11.8

40.0

4.5

4.9

4.4

3.6

3.6

1.1

7. Eucalipto - Global

$9.8 \quad 40.0$

8. Pinheiro - Brasil

$5.5 \quad 7.4$

0.3

4.2

0.6

30

9. Pinheiro - Global

$9.8 \quad 23.0$

4

5

4

43

44

64

5

10. Produtividades Estimadas para o Projeto FLORAM 26

$\begin{array}{lr}\text { Alta } & 13.1 \\ \text { Alta/Média } & 10.1 \\ \text { Média } & 7.3 \\ \text { Média/Baixa } & 4.7 \\ \text { Baixa } & 1.3\end{array}$

11. Média Ponderada das Produtividades Estimadas: 7.5

12. Média "Global" Para Florestas Tropicais: 6.3 


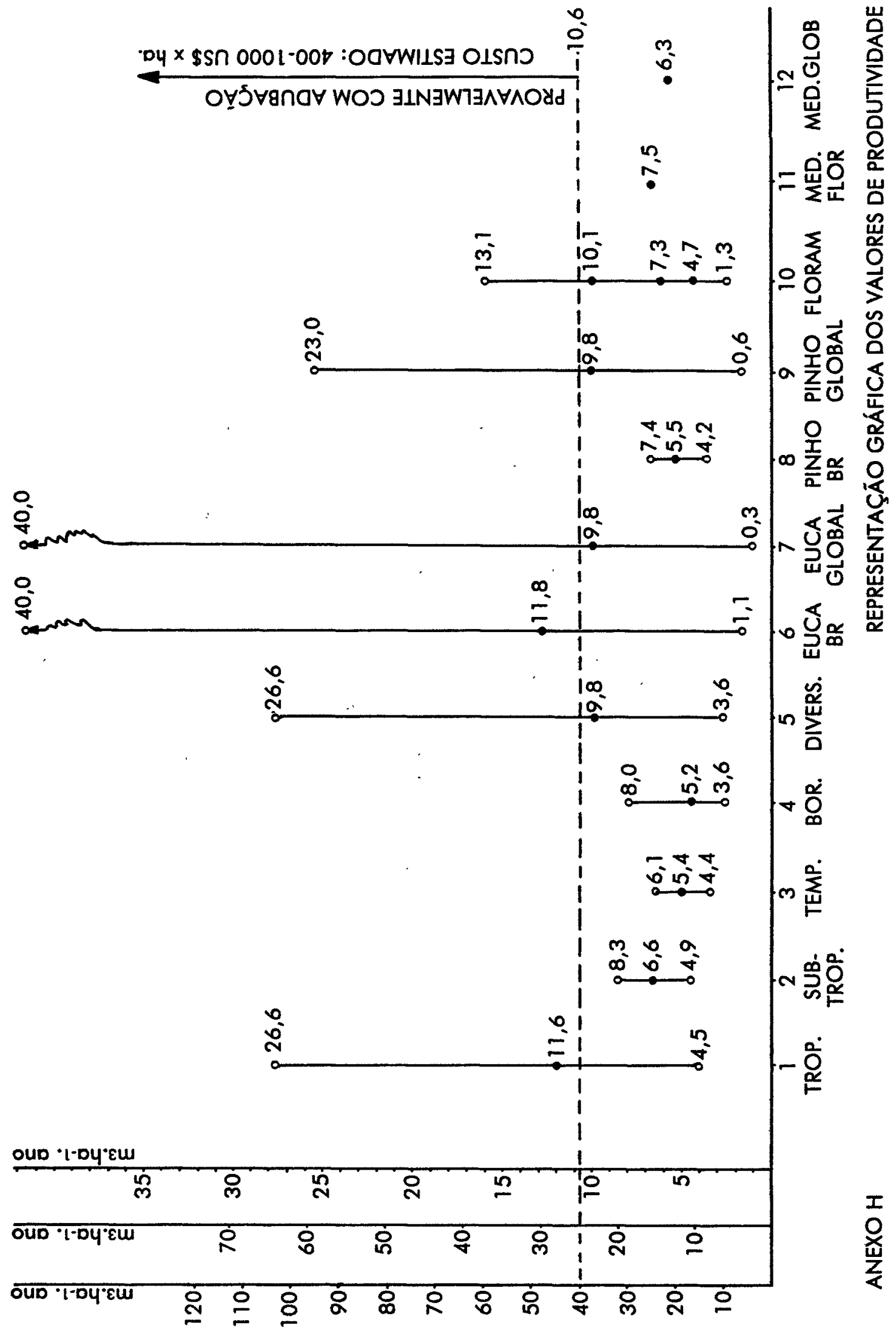


AB'SÁBER, Aziz Nacib

1977 - Dirctrizes para uma poltrica de preservacalo de Rescrvas Naturais no Estado de Sato Pasulo. - Geo-. grafia e Planejamento n. 30, Instituto de Geografia-USP, São Paulo.

1984 - Ecossistemas Continentais.-In: - Relatório da Qualidade de Meio Ambiente", RQMA, SEMA, Brasilia.

1987 - Genese de wana nova regito sideruirgica: acertos e distoréóes de origem na fuixa Carajis/saro Luiz. Pará Desenvolviment n.22 (Jul/Dez.1987), pp. 3-15, IDESP, Belém, Pará.

AB'SABER, A. N., CHACEL, F. M. e TSUKUMO, N.M. J.

1975 - Tratamento Paisagistico da Usina de Paraibura e Barragem de Paraitinga. - Geografia e Planejamento n.17, IGEOG-USP, São Paulo.

\section{ALMEIDA, Álvaro Fernando de \\ 1979 - Florestas implantadas e conserva- sho da natureza: bellso contrasenso ou nopa filosofia. - Engenharia Florestal, n.2, (Jan./Jun. 1979), Pp. 18-32, Piracicaba, SP. \\ 1985 - Plancjamento ambiental no ma- nejo florestal: manutenffio da produtividade. - Espaço Flores- tal n.2, Pp. 50-60, Porto Ale- gre, RS.}

ANFPC - Ass. Nac. FAB. PAPEL E CELULOSE

1988 - Relatorio Estatistico Anual.ANFPC, São Paulo.

ANONIMO (WORKING PAPER N.1) (R-3142)

1976 - Permanent Sample Plot Growth Tronds for $P$. Patula in $U_{g a n-}$ da. - Research Project R-3142. Working paper n.l, Unit of Tropical Sylviculture, Oxford University.

Estudos Avançados, 4(9)
ANÓNIMO (WORKING PAPER N.8)

(R-3142)

1976 - Permanent Sample Plot Growth Tronds for P. Patula in Renye. Research Project R-3142, Working paper n.8, Unit of Tropical Sylviculture, Oxford University.

ARKCOLL, David B.

1979 - Unea avaliagtao das opsóes agrossilviculturais para a Amarbnia. Anais do Simpósio sobre Ciências Básicas e Aplicadas, Publ. da ACIESP, n.19, pp 101-111, Şo Paulo.

AZAMBUJA, D. e THIBAU, C. E.

1973 - Diretrizes para o problema do carpaso pegetal na siderurgia. - Boletim Técnico n.3, IBDF, Brasilia.

BANDHU, D.

1973 - Chakia project. Tropical deciduous forest ecosystem. - In: Kern I, Ed. Modeling forest ecosystems, EDFB-IBP 737, Oak Ridge National Laboratory, Tennesee, USA, (cit. por: BROWN S. e outros, em 1982).

BARRICHELO, Luiz Emesto George

1978 - Apropeitamento de madeiras de florestas maturais do Estado de Santa Catarina para a produsfäo de celulose. - ESALQ/USP, Piracicaba, SP, (Trab. apres. no XI Congr. da ABCP).

1989 - Commonicararo particular. - (23 de Nov. 89), ESALQ-USP.

BATISTA, J. L. F.

1988 - Apontamentos da Sibicultura Urbana. - ESALQ/DCF, Piracicaba, SP.

BAUMGRATZ, S. S. C BOAVENTURA, R. S.

1986 - Erosas acelerada e descrtificagato om Misuas Gerais. -In: "Seminário de Desertificação no 
Nordeste - Documento Final", pp. 84-110. SEMA/Min. do Des. Urbano e Meio Ambiente, Brasflia.

BERTONI, J. E. A. e MARTINS, F. R.

1987 - Composigato Flonistica de sema Floresta Ripdria na Reserva Estadual de Porto Ferreira - SP. Acta Botânica Brasilica, vol.l, n.1, pp. 17-26, Brasilia.

BETTIOL, A. I. e MASLAK, M. I. G.

1973 - Programa de reflorestamonto estaduall 974-1983. -SRNR/Secr. Agric. de Porto Alegre, RS.

BOLIN, Bert

1977 - Cbanges of Land Biota and Their imporance in the Carbon Cycle. Science vol.196, p.613.

BRANDĀO, LEOPOLDO G.

1984 - A man-made Forest. - The Marcus Wallenberg Foundation Simposia Proceedings, p.13, Falun, Suecia.

BRISCOE, C. B.

1979 - Agroforistaria in Jain. Florestades y Agropecuvaria.- Brasil - Actas Taller Sistemas Agroflorestales en America Latina. (Turrialba, Costa Rica). Centro Agron. Tropic. Invest. y Enseñ., CATIE, Turrialba.

1983 - Javi Florestal e Agropecuariai us a depelopment model. - SBPC (35² Reuniāo Anual - Belém, Julho de 1983), Mimeografado.

BRONBANI, E. J. e SILVA L. C. da 1983 - Arborizagato de apudes c barragows. - DRNR (Secretaria da Agricultura do Estado do Rio G. do Sul), Porto Alegre.

BROWN, SANDRA e LUGO, A. E.

1982 - Organic Matuer in tropical Forest artie the Carbon Cycle. - Biotropica 14(3): pp. 161-187.

BRUNIG, E. F.

1968 - On the lints of vegerable productivity in the Tropical Rain -
Forest and the Boreal Coniferous Forest. - Ind. Bot. Soc. 46: pp. 314-322 (cit. por: Jordan C.F., 1983).

BROSCH, Carlos Dias

1976 - Uso de carpdo pegetal no Brasil. In: "Energia no Brasil" (José Goldemberg, Coord.), pp. 53-57.

BRYANT, Alden

1988 - Ten years grap. - World Congress "Climate and Development" ; Hamburg, FRG.

CAMPINHOS JR, $\mathrm{E}$.

1980 - More wood of bettor quality tbrowgh intensipe silvicultipre with rapid-growth improped Brazil ian Eucalyptus. - TAPPI, vol.63, n.11, pp. 145-147.

CARVALHAL, C. $M$.

1989 - Generalidades sobre a fixufuto e consolidafario de ducruas - processos ampregados. - AGROS, vol. 14, n.2, pp. 129-137, Pelotas.

CAVALHEIRO; F., ANDRADE, L. S. L. de A. e CARDOSO, M. A.

1983 - Ecologia urbana: o plangjamento o o ambiente alterado das ridades. - In: Revista do Serviço Público (FUNSEP), ano 40, vol.111, n.4, (Out./Dez.1983), pp. 109-112, Brasflia.

\section{CENTRO DE PLANEJAMENTODA BA-} HIA

1978 - Atlas climatologico do Estudo da Babia: $O$ clima e a organizanga do espafo geogrdfico. - (Dir de C.

A. de Figueiredo Monteiro), Documento síntese - C.B.P. - Secret. de Planej. Ciência e Tecnologia, Salvador.

\section{CHEMRAWN I}

1978 - World Conference on Futwere Sources of Organic Raw Materials. - Toronto, Canadá, Pergamon Press - New York, 1980.

CHIARINI, J. V. e COELHO, A. G. S. 1969 - Coberwura Vegetal Natural e 
Area Reflorestada do Eistodo de Sato Paulo. - Bol. Inst. Agron. n.193, Campinas, SP.

CONGRESSO FI.ORESTAL BRASILEIRO

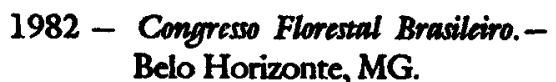

CONGRESSO FLORESTÁL BRASILEIRO

1986 - Congresso Florestal Brasileiro.(28-30 de nov. de 1986), Olinda, PE.

\section{CONGRESSO BRASILEIRO DE ECO-} LOGIA

1978 - Arrais do 10 Comgresso Brasileiro de Ecologia. - Curitiba, PR.

CONGRESSO NACIONAL SOBRE ESSENCIAS NATIVAS

1982 - Congresso Nacional sobre Esthcins Natipas. - (12-18 de set. de 1982), Campos do Jordāo, SP.

\section{COUTO, Hilton Thadeu Zarate do}

1982 - Florestas Tropicais irusilleiras: possibilidades e parpectivas na regitto amazbrica. - IPEF, vol. 1, pp. 185-199, Piracicaba, SP.

DE ANGELIS, D. L., GARDENER, R. H. e SHUGARTH H. H.

1981 - Productivity of forest ecosystems studied during. - IBP: the woodlands, data set, In: D. E. Reichile Dynamic properties of forest ecosystems, IBP: Prog. 23, pp. 567-672. Cambridge University Press, New York, USA, (cit. por: Brown S. c outros, 1982).

EMBRAPA

1980 - Avaliagato de esptcies Eucaliptus (MG - ES). -Boletim de Pesquisa n.l, Junho de 1980.

EMBRAPA

1983 - Apaliagato silpicultural. - Boletim de Pesquisa n.20, Junho de 1983.

ENCONTRO DE PRESERVAÇÃO DE MADEIRAS/ABPM

Estudos Avançados, 4(9)
'1989 - III Encontro (...) - (25-27 de out. de 1989), São Paulo.

ENCONTRO NACIONAL DE CONSERVAÇÃO DA FAUNA E RECURSOS FAUUNISTICOS

1977 - Ancis do Encontro (...) - Brasilia, DF.

ENSCH, L.J.

1953 - Siderurgia baseada a carpato pegetal no Brasil. Possibilidudes e planos de axpanseto. - Geologia e Mineralogia n.10, Pp. 124 147, São Paulo.

EVANS, $\mathbf{j}$.

1982 - Plantation Forestry in the Tropics. -Oxford, Clarendon Press.

FAO - FOOD AND AGRICULTURE ORGANIZATION OF THE UNITED NATIONS

1981 - El Eucalipto en la repoblacion forestal. - Coleción FAO n.II, MONTES.

FAOO - FOODD AND AGRICULTURE ORGANIZATTON OF THE UNITED NATIONS

1988 - Forestry Action Plan for Latin America and the Caribbean. Executive Summary; FAOONU, Roma.

FEARNSIDE, PHILIP $M$.

1987 - Sumemany of progress in quantifying the potential contribution of Amazonian deforestation to the glabal carbon problem. - In: " Bio-geochemistry of Tropical Rainforests: problems for research", CENA (Centro de Energia Nuclear na Agricultura), pp. 75-82, ESALQ-USP, Piracicaba, SP.

1987 - Deforestation and intemational ecomomic depelopment projects in Brazilian Amazeonia. - Conservation Biology I, Pp. 214-221.

1989 - A Amazbia Brasileira no contexco do Programa Internucional Biosfora - Geosfera. - Boletim do Inst. de Geociências-USP, Public. Esp. n.6, pp. 105-111, SP. 
1989 - The Chareoal of Carajds: a' Threat to the Forests of Brazeil's Eastem Amazom Region. AMBIO, vol.18, n.2, pp. 141143.

\section{FERREIRA, Mário}

1983 - Melboramento Florestal e Silpicultura Intensipa com Encalipto. - Silvicultura, Ano VIII, n.29, pp. 5- 11.

1989 - A situafulo florestal brasileira. BSALQ/DCF-USP.

FONSECA S. M., FERREIRA, M. e KAGEYAMA, P. Y.

1979 - Resulades o perspectivess do programa de melbonumento gentitico com aucaliptos conduzidos pelo IPEF na regino Sut do Brasil. IPEF, Boletim Informativo n.7, pp. 1-37.

FRANCO, Emmanuel

1956 - Estudo de Ecologia vegetal e refiorestamento. - Posto de Defesa Agricola em Sergipe, Publ. n.4 (Min. Agric.), Aracajú, SE.

\section{FUNDAÇÅo CENTRO TECNOLÓGI- CO EM MINAS GERAIS - CETEC \\ 1980 - Plano de desenvolvimento inte- grado do nomesse minciro: recuessos netrumis. -2 vols. (CETEC - Publs. Teens., n.2), Belo Hori- zonte.}

1983 - Diagnodstico ambiontul do Estado de Minas Gerair- - CETEC (Publs. Tecns., n.10) 2 vols. Belo Horizonte.

GALVÃO, A. P.M.

1989 - Fitomassa atrea da produstio naturnal de somer floresta tropical timida numarbmica submotida a Corte Raso.- EMBRAPA, Brasilia (Manuscrito não publicado).

GIBBS, P. e LETTÃO Filho, H. F.

1978 - Florestic composition of an area of gallery forest near Mogi Guafur, State of Sto Paulo, SE Brazil. Revista Brasileira de Botânica n.1, PP. 151-156,SP.
GONÇALVES, J. L. M.

1988 - Intenpretaferto de levartamento de solos para fins silviculturais. IPEF, n.39, pp. 65-72, Piracicaba, SP.

\section{GOLDEMBERG, José}

1989 - Amazomin and the greonbouse effect. -In: "Amazonia: facts, problems and solutions", pp. 13-17, USP -INPE, Săo Paulo, SP.

GOLFARI, $\mathrm{H}$.

1980 - Zoneamento Ecológico para Ra-

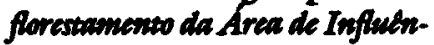
cin da Sorm dos Carajds. CRVD Revista vol.1, n.2, pp. 3-18, Rio de Janeiro.

GOLLEY, F. B. e LIETH, H.

1972 - Bases of Organic Production in the Tropics. -In: Golley P. M. e Golley F. B. - "Tropical Ecology Production": University of Georgia, Athens Ga., Pp. 1-26, (cit. por: Jordan C.F., 1983).

GOLLEY, F. B C MEDNA, E.

1975 - Tropical Ecological systems. Ecological Studies 11, pp. 137 152, Springer - Verlag, New York, (cit. por: Brown S. e outros, 1982).

GOMES, A. M. B., CARVALHO, C. S. de e BARBOSA V. R. D.

1980 - Estudo de Geomorfologia: Alegret, RS. - Instituto de Geociencias, Publicaçăo Avulsa UFRGS, Porto Alegre.

GRUPO ESTRATÉGICO DE PLANEJAMENTO FLORESTAL

1982 - Brasil Florestal, Ano 2000: diretrizes estrategicas para o setor flo. restal brasilairo. - Brasil Floresml, ano 12, n.50 (Maio/Junho, 1982). (Participam do GPEF: Brandżo, Lupatelli, Freitas, Galvăo, Coelho, Terezo, Magalhães Neto, Chaeri, Rodés, Barrichelo, Murat Ir., Machado, Leite, Levy Prange, Tocci, Jacob, Suirer Filho e Marcovitch). 
GOVERNO DO DISTRTTO FEDERAL

1972 - Inventdrio florestal do Distrito Federal. -GDF/ Secr. da Agrc. e Prod., Brasilia.

HALL, D. O. e ROSILLO Calle, F.

1989 - $\mathrm{CO}_{2}$ Cycling biomes: global bioproductirity and problems of deforastation. - In: "Amazonia: facts, problems and solutions", pp. 478527, USP-INPE, São Paulo.

HEINSDIJK, D. L., SOARES, R. D. e BASTOS, $M$.

1962 - Plantagito de confferas no Brasil. Estudo preliminar sobre o Dolume e - rendimento de Araucuria angusti folia, Coyptomeria japonica, Cunninghamia lanceslata e Pinus elliotii. - Setor de Inventário Florestal, Boletim n.51, Rio de Janeiro.

HUBER, J.

1910 - Matas e madeiras amazbnicas. Bol. Museu Goeldi,n.6, pp. 91-225, Belém, Pará.

HÜECK, Kurt

1972 - As Florestas da Ambrica do Sul. - (Trad. de Die Walder Sudamericas Stuttgart, 1966, por Hans Reichardt), Ed. da Universidade de Brasilia e Ed. Polígono, Sáo Paulo, SP.

HÜECK, R. e SEIBERT, P.

1972 - Vegetations Karte pon Sudamerika. - Biogeography and Ecology in South America (Fittkau, E.J. e outros), vol. I, pp. 54-81.

HUTTEL, C. H. e BERNHARD-REVERSAT, F.

1975 - Recherches sour l'ccosystem de la foret sub equatoriale de base COte, $D$ Tpoire - Cycle des matileses organiques. - Terre Vie, 29: pp. 203-228, (cit. por: Brown S. e outros, 1982).

\section{IBDF/DEF}

1983 - Relattrio: Inventdrio dos Reflorestomentos do Estado, Monitoramento dos reflorestomentos do Estado da Bahia. - (maio de
1983). IBDF/DEF., Braslia, DF.

IBDF/DEF

1983 - Relatorio: Apaliagsto econbmica das florestas natipas da regiao Sudeste do Estado de Sá Paulo. -(maiode 1983). IBDF/DEF., Brasilia, DF.

IBDF/DEF

1983 - Relattrio do Inpenttrio das Florestas do Estado, Inventirio dos Reflorestamentos do Estado do Esprrito Sarto, Apaliagắ Econtomica das Florestas Nativas da Regicio Sudeste. - IBDF/DEF., Brasilia, DF.

\section{IBDF/DEF}

1983 - Relatorios: Inpentadio dos Reflorestamentos do Estado, Inventario das Florestas Nativas do Estado de Santa Caturina. - (março de 1983.) IBDF/DEF.,Brastila, DF.

IBDF/DEF

1983 - Relatbrios: Inpentarios dos Reflorestamentos do Estado, Inpentatrio das Florestas Natipas do Estado, Monitoramento dos Reflorestamentos do Estado do Parand. -(marçode1983).IBDEF/DEF., Brasilia, DF.

IBDF/DEF

1983 - Relatorios: Inventdrio das Florestas Nativas, Inventutrio dos Reflorestamentos $C$ Inpentdrio da Floresta Nacional de Săo Francisco de Paula. - (fevereiro de 1983). IBDF/ DEF., Brastia, DF.

\section{IBDF/DEF}

1983 - Relattrio do Inventitio dos Reflorestamentos do Estado de Minas Gerais. - (março de 1983). IBDF/DEF., Brasflia, DF.

1984 - Relathrios: Inpentario Multiesthgio dos Reflorestamentos do Es. tado do Mato Grosso do Sul. Estudo de Altermatipas de Aproveitomento dos Reflorestomentos do Eixo Campo Grarde - Trés La- 
gans. -(junho de 1983). IBDF/DEF., Brasilia, DF.

1984 - Relatorios do Inpentario das Flo. restas Natipas do Estado de Goids. - (dez. de 1984). IBDF/DEF., Brasilia, DF.

IBGE

1988 - Mapa de pegetafáo do Brasil Escala 1:5.000.000. - Secret. de Planej. e Coord. da Pres. da Repúbl., FIBGE/MA/IBDF, Rio de Janeiro.

\section{INSTITUTO BRASILEIRO DE DESEN-} VOLVIMENTO FLORESTAL

1974 - Zoneamento Economico Florestal do Estado de Minas Gerais. IBDF. Min. da Agr. de Belo Horizonte.

1974 - Zoneamento Económico Florestal do Estado do Espirito Santo. IBDF. Minist. da Agr. de Belo Horizonte.

\section{INSTTTUTO ESTADUAL DE FLORES-} TAS (IEF)

1986 - Controle da Explorafắo Florestal em Minas Gerais. - Período de jan. de 1980 a jun. de 1985. Belo Horizonte, MG.

INSTITUTO FLORESTAL - Coord. de Pesq. de Recurs. Nats.

1975 - Zoneamento Economico Florestal do Estado de Sáo Paulo. - Secr. Agric. de São Paulo, Boletim Técnico n.17.

\section{INVENTÁRIOS FLORESTAIS - IBDF- DEF}

1. Inventatrio Florestal Nacional das Florestas Nativas dos Estados do Parand e Santa Catarina.

2. Inventurio Florestal Nacional Reflorestamento, SC.

3. Inpenturio Florestal Nacional Florestas Natipas, $R S$.

4. Inventhio Florestal Nacional Florestas Natipas, RJ/ES

5. Inventdrio Florestal Nacional Reflorestamento, RJ/ES.

6. Inventario Nacional dos Recursos Florestais implanta, oriundos de incentivos fiscais, $S P$.
7. Inventutrio Nacional dos Recursos Florestrais implantados, oriundos de incentivos fiscais, $M S$.

8. Inventdrio Florestal Nacional Reflorestamento, $M G$.

9. Outros Inventidios realizados.

JANKONSKT, Ivaldo $P$.

- A.conserpiafato dos recursos florestais da Amazonia. - Ind. Moveleira, Caxias do Sul, RS.

JORDAN, C. F. e ESCALANTE, G.

1980 - Root productivity in an Amazonian rain forest. -Ecology 61: pp. 14-18, (cit. por: Brown S. e outros, em 1982).

JORDAN, Cart F.

1983 - Productivity of Rain Forest Ecosystoms and the Implications for their use as future wood and Energy Sources. - In: Ecosystems of the world 14A - Tropical Rain Forest Ecosystems, Structure and Function Golley F. B., Editor Elsevier Science Bublishing Co.

KAGEYAMA, Paulo Yoshio

1970 - Crittrios de escolba de especies para utilizanto am pequenas dreas de reflorestamento. -IBDF, Braslia.

1975 - Banco de clones de pinus tropicais: aspectos da fase de enxcertia. -Bol. Inform. IPEF, ano 3, n. 10, pp. 43-52 (Jun.de 1975), Piracicaba, SP.

1980 - Variagágentica em progenies de uma populagfüo de E. grandis Hill (Matiden). - Tese de Doutoramento, ESALQ-USP, 113 pp.

1981 - Sizuaguo de reflorestamento de Pinus no Brasil. -IPEF, Piracicaba, SP.

1984 - Fatores que aftam a productäo de sementes florestais. - IPEF, Piracicaba, SP.

1989 - Plantafoes de especies natipas: florestus de protefato e reflorestamento misto. - ESALQ/DCF., Piracicaba, SP.

Estudos Avançados, 4(9) 
KAGEYAMA, P. Y. e CASTRO, C. F. A.

1986 - Conservactlo gentitica in situ e uso miltiplo da floresta. - Silvicultura, ano 11 , n.41, pp.77-80, São Paulo.

KAGEYAMA, P. Y. e DIAS, I. de S.

1982 - Aplicafáo da gentitica em especies florestais nativas. - Silvicultura em Sāo Paulo, 16 A (parte 2), p. 782-791, São Paulo.

KALLIO, M., DIKSTRA, D. P. e BINKLEY, C. S.

1987 - The Global Forest Sector: an Analytical Perspective. - John Wiley \& Sons.

KENYA NATTONAL FARMERS UNION

1990 - Growing trees for a better future. -Recommended Species for Planting (Ture Masson e David Kamwet). KNFU, Nairobi, Kenya.

KLEIN, R. M.

1966 - Arvores nativas indicadas para 0 reflorestamento no Sul do Brasil. - Sellowia, n.18, pp. 29-39.

KIRA, T., OGAWA, H., YODA, K. e OGI$\mathrm{NO}, \mathrm{K}$

1967 - Comparative ecological studies on three main types of forest pegetation in Thailand, 4. Drymatter production with special reference to the Khaso Chang rain forest. Nature Life Southeast Asia 5: pp. 149-174, (cit. por: Brown, S. e outros, em 1982).

KIRA, T.

1978 - Community architecture and orgasric mattor dymamics in tropical lowland and rain forest of South East Asia, with pecial reforemce to - Pasolb Forest West Malaysia. In: Tom Lison P. B. e Zimmerman M. H.: "Tropical Trees as living systems", Pp. 561-590, Cambridge University Press, New York, USA (cit. por: Brown S. e outros, em 1982).

LAMB, A. F. A.

1968 - Fast growing Timber Trees of the
Lowland Tropics n.1. - Gmelina arborea: Commonwealth Forest Institute. Department of Forestry, University of Oxford.

LAMB, A. F. A.

1973 - Fast Growing Timber Trees of the Lowland Tropics Pinus Caribara. - vol.I, Unit. of Tropical Sylviculture, Department of Forestry, Oxford.

LIEGEL, $L$.

1976 - Results of Triangular Spacing Trials on three differents Soils in Puerto Rico. - Draft n.l, Institute of Tropical Forestry, Rio das Pedras, Puerto Rico.

LIMA, Walter de Paula

1987 - O reflorestamento com eucalipto e seus impactos ambientais. - ARTPRESS, São Paulo.

LIMA, Waiter de Paula

1985 - Afro das chuspas no ciclo biogreoquesmico de nutrientes em plantafóes de pinheiros tropicais en cerradia. - IPEF, n.30, (agosto de 1985), PP. 13-17, Piracicaba, SP.

LIMA, Walter de Paula

1985 - Hidrologia de fiorestas implantadas. -Documentos. EMBRAPA/CNPF, n.16, pp. 8-13, Curitiba, PR.

LIMA, WALTER DE PAULA

1975 - Estrudos de alguns aspectos quantitativos e qualitatipos do balango bldrico em plantrafóes de Eucalyptus e de Pinus. - ESALQ-USP. Tese de Doutoramento, Piracicaba.

LIMA, WALTER DE PAULA

1980 - O Reflorestamento com Exicalipto - sens Impractos Ambicntais. ART-PRESS, São Paulo.

LINDMAN, C. A. M.

1986 - A vegetafato no Rio Grande do Sul. - Livr. Univ. de Porto Alegre. 
LUGO, A. (e outros)

1973 - Tropical Ecosystem structure and function. - In: E. Farnworth e F. B. Golley: "Fragile Ecosystems", Springer-Verlog, Berlin pp. 67-111, (cit. por: Jordan C. F., em 1983).

LUGO, A. E., GONZALES, J. A., CINTRON, B. e DUGGER, $K$.

1978 - Structure, produtivity and transpiration of a sub-tropical diry forest. - Biotropical, 10: pp. 278291 (cit. por: Brown S. e outros, em 1982).

MACIEL, N. C.

1984 - Perspectivas e estrattgias para uma politica nacional de protefato a manguessais e estudrios. - Bol. da FBCN, n.19, pp. 111-125. Rio de Janeiro.

MALAISSE, F., FRESQN, R., GOFFINET, G. e MALAISSEMOUSSET, $M$.

1975 - Litterfall and litter breakdown in Miombo. - In: Golley F. B. e Medina E.: "Tropical ecological systems" . Ecological studies n.11, pp. 137-152, Springer, Verlag, New York, (cit. por: Brown S. e outros, em 1982).

Mc. GAUGHEY, S. e GREGERSEN, H.

1983 - Forest Based Depelopment in Latin America. - BID, Washington D.C.

MEDEIROS, Benjamin A. de

1989 - Brasil versus CO2. -(Trabaiho nāo publicado). Maio de 1989.

MELLO, H. A.

1977 - Madcira, realidade energetica. - IPEF, Piracicaba.

MESA-REDONDA SOBRE REABILITAÇÁO DE AREAS MINERADAS DE XISTOS

1986 - Mesa-Redonda (...) - (27/28 de nov. de 1986), São Mateus do Sul.

MOLLER, O. (e outros)

1975 - Diagnostico sobre a presenfa de manchas de arcia na Regino Su- deste do Rio Grande do Sul. .SUDESUL, Porto Alegre.

MULLER, D. e NIELSEN, J.

1965 - Production brute, pertes par respiration, et production nette, dans In foret ombropbile tropicale. Forst, Fors Vaes. Dann, 29: pp. 69-160, (cit. por: Brown S. e outros, em 1982).

MURPHY, P. G.

1961 - Organic matter and mutrient cycles under moist tropical forest. Plant Soil, 13: pp. 333-346, (cit. por: Porown S. e outros, em 1982).

1975 - Net Primary productivity in Tropical Terrestrial Ecosystems. - In: Leith, H. e Whittakers, R. - Primary Productivity in the Biosphere", Springer-Verlag, Berlin, pp. 217-231, (cit. por: Jordan C. F. C outros, em 1982).

1977 - Rates of Primary Productivity in Tropical Grassland, Savanna and Forest. - GEO-ECO Trop., n. 1: pp. 95-102, (cit. por: Jordan C. F., em 1982).

PANDOLFO, C.

1977 - Potencial madeireiro da Hillia Amazdnica. - In: "Recursos Naturais, Meio Ambiente e Poluição - Contribuiçōes de um ciclode debates" , pp. 197- 205, IBGE SUPREN., Rio de Janeiro.

\section{POGGIANI, Fábio}

1981 - Utilizafáo de espécies florestais de rapido crescimento na recuperafato de dreas degradadas. - Sér. Técn. IPEF, Piracicaba, SP.

1983 - Apectos da dindemica de nutrientes e da productao de biomassa em plantacóes florestais de pinbeiros tropicais. - IPEF, Piracicaba, SP.

1989 - Na Amazbnia, engenhoiro flores tal do pecuarista. - Jornal do Convenio USP/IPEF, ano 2, n. 
28, p.2, (Julho-Agosto de 1989), Piracicaba, SP).

\section{REUNIĀO CONJUNTA IPEF-ASSOCI-} ADAS

1982 - Potencialidades da Regiño Nordeste para a Implantafáo de Florestas de Rápido Crescimento. Salvador, BA. (Tema central da Reuniāo).

RIZZINI, C. T. e COIMBRA Filho, A. F.

1988 - Ecossistemas brasileiros - Brazilian Ecosystems. - Editora Index, Rio de Janeiro.

RIZZINI, C. T. e HERINGER, E. P.

1962 - Preliminares atreas de formafōes vegetais 0 do reflorestamento no Brasil Central. - Serv. de Informs. Agrics., Rio de Janeiro.

RODÉS, Leopold

1988 - A Saga do Jari e seus Ensinamentos - I Jornada Técnica Papeleira (26.05.88). Medellin, Colombia.

RODN, L. E. E BAZILEVICH, N. I.

1967 - Production and Mineral Cycling in Terrestrial Vegetation. - Oliver and Boyd, Edimburg, 288 pp., (cit. por: Jordan C.F., em 1983).

RODRIGUES, João Barbosa

1893 - Hortus fiuminensis. - (Guia para visitantes do Jardim Botânico do Rio de Janeiro).

RUDOLPH, V. J., SIMŌES, J. W. e JAMES, L. M.

1979 - Forestry in Brazil: an awakening giant. -Journal of Forestry, vol.76, n.12, (dez. de 1979).

SÃO PAULO - Secretaria da Agricultura

1970 - Programa Florestal de Sáo Paulo. - Secr. da Agric. de São Paulo.

SANTA CATARINA - Secretaria da Agricultura e Abastecimento

1975 - Estudo das condif̧öes ecológicas e economicas da producfüo de materia-prima em florestamento e reflorestimento. - IBDF (Distr.
Ind. de SC), Fiorianópolis, SC.

SEDJO, R. A.

1984 - An economic assessement of industrial forests plantations. - Forest Ecology and Management, 9 (4): pp. 245-257. In: LIMA, W. de P., 1980.

SIEGENTHALER, U. e OESCHGER, $H$.

- 1978 - Predicting Future Atmospheric Carbon Dioxide Lerels. - Science, vol. 199, p.338.

SEIXAS, Fernando

- Explorafá̃o em plantios de Eucalyperus spp sob diforentes espafamentos. - IPEF. Piracicaba, SP.

SEIXAS, Fernando

1983 - Aspectos atuanis e perspectivas de desenvolvimento em explorafão florestal. - IPEF. Ser. Técn., $n$. 25, pp: 9-14, Piracicaba, SP.

SEIXAS, Fernando

1987 - Exploraftio e transporte de Eucalyptus spp. - IPEF. Piracicaba, SP.

SIMÓES, João Walter

- Produfä́ de madeira em florestas energéticas sob diferentes praticas silviculturais. - IPEF. Piracicaba, SP.

1980 - Produfáo de madeira para energia. - CATI. Campinas, SP.

1981 - Formagão, mancjo e exploraçāo de florestas com especies de rapido crescimento. - IBDF. Brasilia, DF.

1983 - Analise dos metodos silviculturais adotados em florestas implantadas para produfáo de energia. IPEF. Piracicaba, SP.

1983 - Andlise dos metodos silviculturais adotados en florestas implantadas para produscáo de energia. IPEF. Piracicaba, SP.

SIMŌES, J. W., BRANDI, R. M. e MALINOVSKY, J. R. 1976 - Formafăo de florestas com especies 
de rápido crescimento. - PRODEPEF. Ser. Div., n.6, pp. 174, Brasilia, DF.

SIMŌES, J. W., COELHO, A. S. R. (e outros)

1980 - Crescimento e Produfá̃o de Madeira de Eucalipto. - IPEF. 20: pp. 77-97.

SIMPÓSIO BRASILEIRO SOBRE TECNOLOGIA DE SEMENTES FLORESTAIS

1989 - 20 Simpósio Brasileiro (...) - Săo Paulo.

SIMPÓSIO FLORESTAL DE MINAS GERAIS

1970 - Anais do $4^{\circ}$ Simpósio Florestal de Minas Gerais. - Universidade Federal de Viçosa, Viçosa, MG.

\section{SIMPÓSIO INTERNACIONAL SOBRE ALTERNATIVAS PARA O DESMATA- MENTO NA AMAZONNIA \\ 1988 - Alternativas para o Desmata- mento na Amazónia. - (Janeiro de 1988). Belém, PA.}

\section{SIMPÓSIO SOBRE MATA CILIAR}

1989 - Simpósio sobre mata ciliar. Instituto de Botânica, São Paulo, SP.

\section{SIMPÓSIO SOBRE EXPLORAÇĀO DE PEQUENOS MACIÇOS FLORESTAIS \\ 1978 - Simposio sobre exploracão de pe- quenos macifos florestais. - (12- 22 de set. de 1978). CATI. Campinas, SP.}

SIMPÓSIO IUFRO SOBRE MELHORAMENTO GENÉTICO E PRODUTIVIDADE DE ESPÉCIES FLORESTAIS DE RÁPIDO CRESCIMENTO

1980 - Simpósio IUFRO (...) - Agosto de 1980. Aguas de São Pedro, SP.

SIQUEIRA, Joésio Deoclécio Pierin

1986 - Viš̈̈o Geral dos Inventírios Florestais no Brasil. - In: "Simpósio sobre a Caatinga e sua Exploraçăo Racional", pp.217241. Univ. Estad. de Feira de Santana. EMBRAPA, Brasilia, DF.
SUDENE/DRN - CONDESE/CRN

1976 - Zoneamento ccológico-florestal do Estado de Sergipe. - SUDENE/DRN e CONDESE/CRN. (Relatório e Carta de Vegetação). Publ. pelo Convênio, Aracaju, SE.

TATO, L., SOUZA, P. F. de e COELHO, A. P.

1951 - Plano de reflorestamento para as usinas sideriirgicas do centro do pats. - Serv. Flor., Rio de Janeiro.

THIBAU, C. E.

1972 - Consimo de carpão regetal em Minas Gerais, relacionado com a produçäo de gusa. - Revista Brasil Florestal, n.12.

TRICART, JEAN

s/d - Problemas de conserpacáo de terras e de dguas nos municipios de Alegrete e São Francisco de Assis. - SUDESUL, Relatório de Viagem, Porto Alegre, RS.

TOMAZELLO Filho, Mário

1982 - Vegetaç̄öo brasileira: morfologia, dendrologia e identificafão demadeiras. -CPRN. São Paulo, SP.

VEIGA, A. A.

1972 - Curso de atualizaç̃̃o Florestal. - 2 ed., Instituto Florestal (SP), vol.1, Rio de Janeiro.

VIANA, Virgilio Maurício

1989 - Seed dispersal and gap regeneration of three tropical species. - Tese de Doutorado. Cambridge.

VICTOR, M. A. M., KRONKA, F. J. N. e NEGREIROS, O.C.

1989 - Evolufäo, estágio atual e perspectivas das florestas exóticas em São Paulo. Instituto Florestal, Boletim Técnico IF n.l, São Paulo.

VICTOR, M. A. M. (e outros)

1981 - Elenco de medidas para promover - reflorestamento e a conservacáa dos recursos florestais en Säo Paulo. - Parte I - Diagnose. Instituto Florestal, Săo Paulo (mimeogr.).

Estudos Avançados, 4(9) 
VICTOR, M. A. M.

1987 - É bora de avaliar o reflorestamento. -Silvicultura, ano I, maio-junho de 1977.

VICTOR, M. A. M. (e outros)

1986 - Land classification for industrial afforestation in the State of SR̃o Paulo, Brazil. - In: "Forest site and productivity", GESSEL, pp. 69-91, Martins Nijhoff Publ. Dordrecht.

VOLTATO, E. (e outros)

1987 - As consequiências sociais,econômicas e ambientais da siderurgia a carnaio pegetal na Amazónia Oriental. - Pará Desenvolvimento, n.22, (jul./dez. de 1987), pp. 25-30, IDESP. Belém do Pará.

WESTLAKE, D. F.

1963 - Comparison of Plant Productivity. - Biol. Rev. n. 38, pp. 385-425, (In: Jordan C.F., 1983).
WHITTAKER, R. H. e LIKENS, G.

1975 - The Biosphere and Man. - In: H. Lieth e Whittaker R.: "Primary Production of the Biosphere ", Springer-Verlag, Berlin, pp. 305-328.

WOODWELL, G. M. (e outros)

1978 - The Biota and the World Carbon Budget. -Science, vol.199, p.14.

YAMAZOE, GUERJI (e outros)

1988 - Avaliąَ̧̃o de programa de reflorestamento de pequenos e médios. - Secr. de Estado de Meio Ambiente - CPRN. (Trab. apres. no I Encontro Brasileiro de Economia Florestal - Curitiba, maio de 1988). Instituto Florestal, São Paulo.

ZOBEL, B., CAMPINHOS, E. e IKEMO$\mathrm{RI}, \mathrm{Y}$.

1983 - Tappi J.jan. 1983. 